DOI: 10.1002/ ((please add manuscript number))

Article type: Full Paper

\title{
Urea-modified Carbon Nitrides: Enhancing Photocatalytic Hydrogen Evolution by Rational Defect Engineering
}

Vincent Wing-hei Lau, Victor Wen-zhe Yu, Florian Ehrat, Tiago Botari, Igor Moudrakovski, Thomas Simon, Viola Duppel, Elise Medina, Jacek Stolarczyk, Jochen Feldmann, Volker Blum, and Bettina V. Lotsch*

Dr. V.W. Lau, Dr I. Moudrakovski, V. Duppel, E. Medina, Prof. B.V. Lotsch Address line 1, Max Planck Institute for Solid State Research, Heisenbergstraße 1, 70569 Stuttgart, Germany E-mail: $\underline{\text { b.lotsch@fkf.mpg.de }}$

V.W. Yu, Dr. T. Botari, Prof. V. Blum

Department of Mechanical Engineering and Materials Science, Duke University, Durham, North Carolina 27708, USA

F. Ehrat, T. Simon, Dr. J. Stolarczyk, Prof. J. Feldmann

Photonics and Optoelectronics Group, Department of Physics and Center for Nanoscience (CeNS), Ludwig-Maximilians-Universität (LMU), Amalienstraße 54, 80799 Munich, Germany

F. Ehrat, T. Simon, Dr. J. Stolarczyk, Prof. J. Feldmann, Prof. B.V. Lotsch

Nanosystems Initiative Munich (NIM), Schellingstr. 4, 80799 Munich, Germany

Prof. B.V. Lotsch

Department of Chemistry, University of Munich, Butenandtstraße 5-13, 81377 Munich, Germany

Keywords: Graphitic Carbon Nitride, Photocatalysis, Solar Hydrogen, Rational Catalyst Design, Metal-Support Interaction

Abstract: The primary amine groups on the heptazine-based polymer melon, also known as graphitic carbon nitride $\left(\mathrm{g}-\mathrm{C}_{3} \mathrm{~N}_{4}\right)$, can be replaced by urea groups using a two-step postsynthetic functionalization. Under simulated sunlight and optimum Pt loading, this ureafunctionalized carbon nitride has one of the highest activities among organic and polymeric photocatalysts for hydrogen evolution with methanol as sacrificial donor, reaching an apparent quantum efficiency of $18 \%$ and nearly 30 times the hydrogen evolution rate compared to the non-functionalized counterpart. In the absence of Pt, the urea-derivatized material evolved hydrogen at a rate over four times that of the non-functionalized one. Since "defects" are conventionally accepted to be the active sites in graphitic carbon nitride for 
photocatalysis, the work here is a demonstrated example of "defect engineering", where the catalytically relevant defect is inserted rationally for improving the intrinsic, rather than extrinsic, photocatalytic performance. Furthermore, our work provides a retrodictive explanation for the general observation that $\mathrm{g}-\mathrm{C}_{3} \mathrm{~N}_{4}$ prepared from urea performed better than those prepared from dicyandiamide and melamine. In-depth analyses of the spent photocatalysts and computational modelling suggest that inserting the urea group causes a metal-support interaction (MSI) with the Pt co-catalyst, thus facilitating interfacial charge transfer to the hydrogen evolving centers.

\section{Introduction}

Photocatalytic hydrogen evolution from water provides a direct method to capture and store sunlight as chemical energy, which can then be released in an environmentally friendly energy cycle. While a large library of photocatalytic materials has been catalogued ${ }^{[1]}$ in the four decades since Honda's and Fujishima's report on photocatalytic water-splitting by $\mathrm{TiO}_{2},{ }^{[2]}$ one of the most promising photocatalysts is the heptazine-based graphitic carbon nitride $\left(\mathrm{g}-\mathrm{C}_{3} \mathrm{~N}_{4}\right)$, historically known since Liebig's era as melon. ${ }^{[3]}$ Melon is a 1-dimensional polymer of heptazine, bridged by secondary amines, with neighbouring polymer strands hydrogen-bonded together into quasi 2-dimensional arrays that form stacks through $\pi$ - $\pi$ interaction (Scheme 1, left) ${ }^{[4]}$ Graphitic carbon nitride has also been depicted in the literature as a fully condensed 2D layered structure with tertiary amines bridging every heptazine unit (Scheme 1, middle), ${ }^{[5]}$ although this fully condensed material has not been unambiguously shown to form experimentally to date. In 2009, the related yet fully 2-dimensionally linked framework, poly(heptazine imide) or PHI, was reported (Scheme 1, right). PHI has a hexagonal network where each heptazine forms three secondary amine bonds with neighbouring heptazine units. ${ }^{[6]}$ 
Graphitic carbon nitride as a photocatalyst has the advantages of being easily prepared from inexpensive precursors (melamine, dicyandiamide or urea) ${ }^{[7]}$ having appropriate energy levels straddling the redox potential required for water-splitting, ${ }^{[8]}$ functioning under visible light irradiation, and being chemically stable. Overcoming one of its major disadvantages its still moderate activity - is the subject of research in the numerous reports on carbon nitride photocatalysis. Most of the publications on graphitic carbon nitride thus far focus on three main strategies for activity enhancement: 1) red-shifting the absorption onset through copolymerisation with dopant(s),$\left.{ }^{[9]} 2\right)$ texturization for surface area increase, ${ }^{[10]}$ and 3) composite formation with a (semi)conductor for improving photo-excited charge separation. ${ }^{[1]}$ While useful, there is a striking lack of attempts to enhance the intrinsic activity of carbon nitrides, which is aggravated by the limited molecular tunability of carbon nitrides due to their insolubility and lack of reactivity. Here, the terms intrinsic and extrinsic with respect to the catalytic properties are differentiated based on the definition proposed by Vojvodic and Nørskov: intrinsic refers to the chemical composition and structure of the catalyst material, whereas extrinsic refers to either geometrical structuring (strategy 2 above) and/or its interface with another solid material, liquid or gas to influence the host catalyst (strategy 3 above) ${ }^{[12]}$ At the same time, improving the interfacial transfer of photo-excited charges to the reactants - via the co-catalyst - constitutes an important yet somewhat overlooked strategy for improving photocatalytic activity. ${ }^{[13]}$ Even in the very efficient CdSePt system, it is estimated that only $40 \%$ of the photo-excited electrons are transferred to the platinum from spherical CdSe particles, ${ }^{[14]}$ a prerequisite step for hydrogen evolution. We and others have shown that the carbon nitride photocatalysts can function with a range of hydrogen evolving electrocatalysts that are synthetic, biological or bio-inspired, with activity rivalling that of platinum, ${ }^{[15]}$ even though the coupling between these catalysts and the polymer is rather weak. ${ }^{[15 e]}$ To address this, we have investigated the structural features that 
lead to photocatalytic activity in amorphous melon as opposed to crystalline melon, which exhibits negligible activity. ${ }^{[16]}$ Unlike crystalline melon, which is prepared in a sealed ampoule under autogeneous ammonia pressure leading to reversible reaction conditions and crystal defects healing, we have previously shown ${ }^{[17]}$ that amorphous melon contains crystal imperfections in the form of dangling moieties resulting from incomplete cyclisation and polymerisation, or impurities (e.g. oxygen) from the precursor. Using the methodology of model photocatalysts, we identified the functional groups that may be considered as the "defects" responsible for photocatalytic activity, namely the cyanamide moiety $\left(-\mathrm{NCN}^{-}\right)$and oxygen-bearing functional groups $\left(-\mathrm{O}^{-},-\mathrm{COOH}\right)$, which can be present due to incomplete cyclization of the heptazine or incorporation of oxygen from the atmosphere or precursor.

Using this knowledge, we were furthermore able to demonstrate the concept of active site engineering for activity improvement, that is, the rational insertion of the catalytically relevant "defect" into the heptazine structure. This concept was illustrated by converting the primary amines of melon into the anionic cyanamides, one of the "defects" identified, through a post-synthetic treatment with $\mathrm{KSCN}$ to yield a material (henceforth notated as $\mathrm{NCN}-\mathrm{CN}_{\mathrm{x}}$; see Scheme 2) outperforming melon by over 12 times at optimum Pt loading. ${ }^{[17]}$ Note that, in Scheme 2, we have depicted only the site where the incorporated functional group is present, which is either at every heptazine unit assuming a 1D polymeric heptazine backbone, or at the periphery of the 2D network array of PHI (Scheme S1). The roles of such "defects" may be to: 1) act as the reduction or oxidation reaction sites; ${ }^{[18]}$ 2) facilitate intermolecular interactions to improve overall reaction kinetics through increased catalystsubstrate affinity, ${ }^{[15 f]} 3$ ) modify energy levels or carrier dynamics, ${ }^{[17]}$ and/or 4) enable strong photocatalyst/co-catalyst interactions to facilitate charge transfer. ${ }^{[17]}$ 
As the cyanamide group can be hydrolyzed to urea, ${ }^{[19]}$ we here exploit this synthetic

procedure to introduce an oxygen-containing group into the heptazine polymer, since our previous work identified oxy- or carboxylate as groups potentially relevant for photocatalysis. ${ }^{[17]}$ The obvious advantage of this route is that, unlike heating the precursor in oxygen or incorporating a dopant stochastically into the polymer, an oxygen-containing moiety such as urea can be controllably inserted at the peripheral sites of the heptazine units, thus facilitating characterization of the polymer for elucidating structure-activity relationship. As will be shown here, this hydrolysis product - notated as urea- $\mathrm{CN}_{\mathrm{x}}-$ exhibits photocatalytic activity for hydrogen evolution outperforming even that of $\mathrm{NCN}-\mathrm{CN}_{\mathrm{x}}$ and melon despite absorbing less in the visible region. The role of the urea moiety is rationalized based on experimental and computational findings. Lastly, we provide a retrodictive explanation of why melon has higher activity when synthesized from urea compared to dicyandiamide or melamine ${ }^{[20]}$ based on the structural characterization of urea- $\mathrm{CN}_{\mathrm{x}}$. This finding has particular importance given that a number of carbon nitride systems capable of complete water splitting employed melon prepared from urea, while those prepared from other precursors (e.g. dicyandiamide) exhibited low water-splitting activity. ${ }^{[21]}$ Hence, the results herein highlight the implications of the approach of "defect engineering" for systematically improving carbon nitride photocatalysts.

\section{Results \& Discussions}

Since strong acids are known to catalyze the hydrolysis of cyanamides to form urea ${ }^{[19 a]}$ the $\mathrm{NCN}-\mathrm{CN}_{\mathrm{x}}$ (experimental details in the supporting information) is assumed to undergo hydrolysis at the cyanamide sites specifically when treated with $\mathrm{HCl}$. This acid-treated material, which we tentatively notate henceforth as urea- $\mathrm{CN}_{\mathrm{x}}$, was evaluated for photocatalytic hydrogen evolution under simulated sunlight (AM1.5) under a range of conditions, as shown in Figure 1. At the optimized Pt loading of $2 \mathrm{wt} \%$, deposited in-situ by 
the photo-reduction of $\mathrm{H}_{2} \mathrm{PtCl}_{6}$, and using methanol (10 vol\%) as the electron donor, the urea$\mathrm{CN}_{\mathrm{x}}(20 \mathrm{mg})$ exhibited a stable hydrogen evolution rate of $56.2 \mu \mathrm{mol} \mathrm{h}^{-1}$ for over $100 \mathrm{~h}$ of irradiation, more than doubled the stable rate of $\mathrm{NCN}-\mathrm{CN}_{\mathrm{x}}\left(24.7 \mu \mathrm{mol} \mathrm{h}{ }^{-1}\right.$, optimized at $8 \mathrm{wt} \% \mathrm{Pt})$ and almost thirty times that of melon $\left(2.0 \mu \mathrm{mol} \mathrm{h}^{-1}\right.$, optimized at $\left.1 \mathrm{wt} \% \mathrm{Pt}\right) . \mathrm{In}$ terms of apparent quantum efficiency (AQE) at $400 \mathrm{~nm}$, urea- $\mathrm{CN}_{\mathrm{x}}$ has a value of $17.9 \%$, nearly double that of $\mathrm{NCN}-\mathrm{CN}_{\mathrm{x}}$ at $9.3 \%$ and nearly 36 times higher than that of melon at $0.5 \%$. These performance metrics are summarized in Table S3; the action spectra of the three catalysts are shown in Figure 2b. Though caution must be exercised when comparing literature results, ${ }^{[22]}$ the urea- $\mathrm{CN}_{\mathrm{x}}$ here exhibits one of the highest activities for the sacrificial hydrogen evolution half reaction amongst organic and polymeric visible-light photocatalysts (comparison with literature values given in Table S4) both in relative terms (i.e. outperformance over a photocatalyst standard) as an IUPAC recommendation, ${ }^{[23]}$ or in absolute terms using quantum efficiency as the performance metric as suggested by researchers in the field. ${ }^{[24]}$ Note that higher quantum yields are generally obtained when triethanolamine is used due to its more reductive potential, current doubling and other effects; ${ }^{[25]}$ we nonetheless did not select this electron donor for activity benchmarking as it is light sensitive, often contains optical impurities, and has a complex photo-oxidation mechanism involving many intermediates, ${ }^{[26]}$ as compared to the well-studied, clean photooxidation of methanol. ${ }^{[27]}$ Furthermore, we have also observed that a number of photocatalysts exhibiting high activity with triethanolamine perform poorly with other electron donors such as methanol (Table S4).

The urea- $\mathrm{CN}_{\mathrm{x}}$ can evolve hydrogen photocatalytically using a range of different electron donors (Figure 1c); in the absence of electron donor, trace amounts of hydrogen were detected after over $12 \mathrm{~h}$, albeit just over the detection limit of our GC. More significantly, 
urea- $\mathrm{CN}_{\mathrm{x}}$ evolved hydrogen photocatalytically even without the addition of Pt co-catalyst (Figure 1d), with an average rate in the first $24 \mathrm{~h}$ of $17 \mathrm{nmol} \mathrm{h}^{-1}$, over four times that of NCN$\mathrm{CN}_{\mathrm{x}}\left(4.2 \mathrm{nmol} \mathrm{h}^{-1}\right)$ and melon $\left(3.5 \mathrm{nmol} \mathrm{h}^{-1}\right)$. The apparent correlation between the BET surface area and hydrogen evolution rate of urea- $\mathrm{CN}_{\mathrm{x}}$ and melon suggests that surface area is one key determinant for activity in the Pt-free case. Insertion of Pt co-catalyst, however, changes the contribution of this factor substantially, as the surface area no longer sufficiently accounts for the high activity of urea- $\mathrm{CN}_{\mathrm{x}}$. Based on the comparison of the hydrogen evolution rate at optimized Pt loading normalized to the BET surface area, urea-CN $\mathrm{CN}_{\mathrm{x}}$ evolves hydrogen at a rate of $43.5 \mu \mathrm{mol} \mathrm{h}{ }^{-1} \mathrm{~m}^{-2}$, far outperforming $\mathrm{NCN}-\mathrm{CN}_{\mathrm{x}}$ at $22.5 \mu \mathrm{mol} \mathrm{h} \mathrm{m}^{-1}$ and melon at $6.1 \mu \mathrm{mol} \mathrm{h}^{-1} \mathrm{~m}^{-2}$, as summarized in Table S3. Notably, the superior photocatalytic activity of urea-CN $\mathrm{CN}_{\mathrm{x}}$ cannot be attributed to increased light collection since, from their action spectra in Figure 2b, it has an absorption onset of around $435 \mathrm{~nm}$, which is blue-shifted by $25 \mathrm{~nm}(0.15 \mathrm{eV})$ from that of melon and $\mathrm{NCN}-\mathrm{CN}_{\mathrm{x}}$, both with onset at $460 \mathrm{~nm}$. Rather, urea$\mathrm{CN}_{\mathrm{x}}$ is utilizing the fewer absorbed photons far more efficiently for the desired redox reaction than the other two samples, given that the solar irradiance peaks at around $500 \mathrm{~nm}$.

Collectively, these observations point towards an intrinsic improvement in photocatalytic performance which, as shown below, is attributable to the structural features of urea- $\mathrm{CN}_{\mathrm{x}}$ and their role in the photocatalytic reaction.

Urea- $\mathrm{CN}_{\mathrm{x}}$ was characterized by spectroscopic methods and the results are shown in Figure 2. All solid-state ${ }^{13} \mathrm{C}$ and ${ }^{15} \mathrm{~N}$ NMR experiments (Figure $2 \mathrm{c}$ and $\mathrm{d}$, respectively) were performed using the sample prepared from isotope-enriched $\mathrm{KS}^{13} \mathrm{C}^{15} \mathrm{~N}$, with the enriched samples showing identical FTIR spectra except for the isotope shifts (Figure S3), and compared against ${ }^{13} \mathrm{C}$ and ${ }^{15} \mathrm{~N}$ enriched urea. Urea- $\mathrm{CN}_{\mathrm{x}}$ retained its heptazine character, as evidenced by the ring-sextant out-of-plane bending vibration in the IR $\left(809 \mathrm{~cm}^{-1}\right)$, the signals associated 
with the central (-217.6 ppm) and outer heptazine nitrogen atoms (N1: $-175.2 \mathrm{ppm})$ in the ${ }^{15} \mathrm{~N}$ NMR spectra, as well as the inner (C2: $158.2 \mathrm{ppm})$ and outer (C1: $164.1 \mathrm{ppm})$ carbon atoms in the ${ }^{13} \mathrm{C}$ NMR spectra. ${ }^{[28]}$ The characteristic signals for the $2^{\circ}$ amine bridging the heptazine units are observable in the IR (1308 and $\left.1212 \mathrm{~cm}^{-1}\right)^{[29]}$ and in the ${ }^{15} \mathrm{~N}$ spectra (N3: -240 ppm), while the absence of $\mathrm{a}^{15} \mathrm{~N}$ signal at $-265 \mathrm{ppm}$ indicates the complete conversion of the melon primary amine into cyanamide in the first step of Scheme $2 .{ }^{[3 a]}$ The presence of the urea group can be identified by its characteristic FTIR signals at 1653,1579 and $1549 \mathrm{~cm}^{-1}$, the carbonyl signal (C3) at $\approx 166 \mathrm{ppm}$ as a signal tail to signal $\mathrm{C} 1$, and the urea $-\mathrm{NH}_{2}$ signal (N4) at $-290 \mathrm{ppm}$. Compared to urea, the ${ }^{13} \mathrm{C}$ and ${ }^{15} \mathrm{~N}$ chemical shifts of urea- $\mathrm{CN}_{\mathrm{x}}$ are slightly shifted downfield, which we attribute to deshielding induced by the electron poor heptazine ring. To confirm the NMR assignments, we performed cross polarization with polarization inversion ${ }^{[30]}$ (CPPI, Figure 2e) and double correlation ${ }^{1} \mathrm{H}_{-}{ }^{15} \mathrm{~N}-{ }^{13} \mathrm{C}$ 2D NMR experiments (Figure 2f). For the CPPI experiment, the lack of decay for N1 (outer heptazine nitrogen) and N2 (central heptazine nitrogen) is consistent with the absence of directly bonded protons, which identifies these nitrogens as the tertiary nitrogens of the heptazine ring. The decay of $\mathrm{N} 3$ with a crossover point of $\approx 0$ is consistent with the $\mathrm{NH}$ group, while the decay of $\mathrm{N} 4$ has a crossover point of $\approx-0.5$ and is close to the theoretical value of $-1 / 3$ for $\mathrm{NH}_{2}$. For the double correlation experiment, long distance couplings are observed with the NMR parameters used. Nonetheless, coupling of $\mathrm{N} 4$ to both $\mathrm{C} 1$ and $\mathrm{C} 2$ is consistent with a urea at a heptazine terminal. From the elemental analysis (Table 1), the $\mathrm{C}: \mathrm{N}$ atomic ratio of 0.70 for urea- $\mathrm{CN}_{\mathrm{x}}$ is consistent with both a 1D polymeric structure (Scheme S1 bottom left) and the idealized PHI network structure (Scheme S1 bottom right) with a C:N ratio of $<0.706$. The near absence of potassium signifies that the bulk of the compound is not ionic as in $\mathrm{NCN}-\mathrm{CN}_{\mathrm{x}}$, although the residual potassium can be associated with the presence of unreacted $\mathrm{NCN}-\mathrm{CN}_{\mathrm{x}}$, which may be buried within the polymer and inaccessible to the acid. This unreacted species is 
discernible by the small FTIR signal at $2180 \mathrm{~cm}^{-1}$ (see Figure S2 for enlarged spectra of this region), the broad signal between $125-102 \mathrm{ppm}$ in the ${ }^{13} \mathrm{C}$ spectrum (Figure $2 \mathrm{c}$ inset) and at $\approx-280 \mathrm{ppm}$ in the ${ }^{15} \mathrm{~N}$ spectrum, corresponding to the NCN moiety in $\mathrm{NCN}-\mathrm{CN}_{\mathrm{x}}$.

Characterization of urea- $\mathrm{CN}_{\mathrm{x}}$ by electron microscopy (TEM and SEM), XRD and sorption analyses (Figure 3) shows that this material consists of platelets with lateral dimensions of 40-80 nm. Its nanoscale morphology leads to a comparatively large BET surface area of nearly $65 \mathrm{~m}^{2} \mathrm{~g}^{-1}$ with mainly textural (inter-particle) porosity in the nanometer range, which was achieved without employing sacrificial hard templates. The short interlayer spacing of $3.2 \AA$ and structural periodicity of 11 and $8.6 \AA$ are observable in the TEM, XRD and electron diffraction patterns, and are identical to that of $\mathrm{NCN}-\mathrm{CN}_{\mathrm{x}}$, indicating that the acid hydrolysis did not affect the general macroscopic structure. Additionally, like $\mathrm{NCN}-\mathrm{CN}_{\mathrm{x}}$, urea- $\mathrm{CN}_{\mathrm{x}}$ has around $20 \mathrm{wt} \%$ water based on its thermogravimetric analysis (Figure $\mathrm{S} 3$ ). Otherwise, one noticeable difference is the reduced $d$-spacing for urea- $\mathrm{CN}_{\mathrm{x}}$ of $8.6 \AA$, compared to $9.0 \AA$ for $\mathrm{NCN}-\mathrm{CN}_{\mathrm{x}}$, a decrease which may be related to tighter packing as the urea group can form hydrogen bonds with neighboring heptazine units. As consistent with this explanation, we observe in the $2 \mathrm{D}^{15} \mathrm{~N}-{ }^{13} \mathrm{C}$ spectrum that the urea $\mathrm{NH}_{2}(\mathrm{~N} 4)$ couples not only to the urea carbon $\mathrm{C} 3$ and the outer heptazine carbon $\mathrm{C} 1$, but also couples over longer distance to the inner heptazine carbon $\mathrm{C} 2$.

In order to analyze the charge transfer properties of urea- $\mathrm{CN}_{\mathrm{x}}$, the steady-state photoluminescence (PL) spectra were acquired for $1 \mathrm{mg} \mathrm{mL}^{-1}$ aqueous suspensions of melon and urea-CNx upon excitation at $375 \mathrm{~nm}$ (Figure 4a). The latter exhibited reduction of the PL signal by $83 \%$ compared to melon. Such inverse relationship between photocatalytic activity and PL intensity is commonly observed in many photocatalysts ${ }^{[31]}$ and is usually understood 
in terms of a competition for photoexcited charges between the radiative and charge separating channels. The charge transfer pathway leading to hydrogen generation can be considered as an additional or more efficient non-radiative channel, leading to a decrease in luminescence. The time-resolved PL measurements (Figure 4b) show a much faster PL decay for urea- $\mathrm{CN}_{\mathrm{x}}\left(\tau_{1 / \mathrm{e}}\right.$ lifetime of $\left.0.77 \mathrm{~ns}\right)$ than for melon ( $\tau_{1 / \mathrm{e}}$ lifetime of $\left.2.4 \mathrm{~ns}\right)$. Taken together with the reduced PL quantum yield of urea- $\mathrm{CN}_{\mathrm{x}}$, they indicate a 3-4 fold faster non-radiative recombination rate in urea- $\mathrm{CN}_{\mathrm{x}}$ than in melon, in agreement with the above interpretation. ${ }^{[32]}$

Interestingly, as shown in Figure 4c (spectra shown in Figure S4), the addition of an electron acceptor (decoration with Pt) or a hole acceptor (10 vol\% methanol) to either of the two materials results in only very moderate (10-15\%) quenching of the PL; the apparent increases in PL intensity upon addition of methanol to the platinized samples are within experimental error. The corresponding PL decay traces (Figure $4 \mathrm{~d}$ and e) show no change upon the addition of Pt or methanol, even though the presence of a co-catalyst and a hole scavenger strongly increases the photocatalytic efficiency. These results are unusual since in CdS-based photocatalysts, for example, the decoration with co-catalyst strongly quenches PL and leads to much faster signal decay. ${ }^{[33]}$ This suggests that in the first step the photoexcited charges transfer to the internal site on the polymer, presumably the pendant primary amine and urea moiety on melon and urea- $\mathrm{CN}_{\mathrm{x}}$, respectively. The lack of correlation between the PL decay rate and the presence of Pt means that this initial step is independent (i.e. proceeds on a different time scale) of the subsequent electron transfer to Pt and onwards to a proton, and does not constitute the limiting step of the hydrogen generation process. Consequently, the difference in photocatalytic efficiency between melon and urea- $\mathrm{CN}_{\mathrm{x}}$ possibly arises from different transfer rates from the internal site to the Pt particle (or directly a proton in case of a non-platinized system), depending on the coupling between this site and the Pt particle. 
To further explore the rationale for the high performance of urea- $\mathrm{CN}_{\mathrm{x}}$, namely the role of the urea moiety and its interaction with the Pt co-catalyst, the spent catalyst with the Pt photodeposited in-situ after the $100+$ hour photocatalytic experiment was fully characterized (Figure 5). The FTIR and ${ }^{13} \mathrm{C}$ NMR spectra and the XRD patterns are essentially identical between the pristine and the spent catalyst, demonstrating chemical and morphological stability of urea-CN $\mathrm{N}_{\mathrm{x}}$ after the photocatalytic reaction. In the ${ }^{15} \mathrm{~N}$ CP ssNMR spectrum, appearance of peak shoulders for N1, N3 and possibly at N4 can be attributed to the presence of the Pt co-catalyst and will be elaborated below. Similarly for the XPS, the general peak shapes are largely unchanged after the photocatalytic reaction, although small shifts in the binding energies are observed. Briefly, assignment of the deconvoluted XPS signals, based on previous publications, is as follows. The signals for the heptazine $\mathrm{sp}^{2}$ carbons and nitrogens occur at 288.6 and $399.1 \mathrm{eV}$, while the $\mathrm{sp}^{3}$ nitrogen of the bridging $2^{\circ}$ amine occurs at $400.8 \mathrm{eV} \cdot{ }^{[34]}$ The $\mathrm{C} 1 \mathrm{~s}$ signal at $286.5 \mathrm{eV}$ may be assigned to the $\mathrm{sp}^{2}$ carbon of urea, while the broad signal at $293.6 \mathrm{eV}$ is attributed to potassium associated with unreacted cyanamide anion from $\mathrm{NCN}-\mathrm{CN}_{\mathrm{x}}$. As illustrated in Figure 5, some $\mathrm{C}$ and $\mathrm{N}$ signals as well as the oxygen signal from urea are shifted to higher binding energy (B.E.), with the oxygen shifting by $0.3 \mathrm{eV}$, well above the resolution of the XPS. For the in-situ deposited Pt, the Pt XPS $4 \mathrm{f}_{7 / 2}$ signal can be deconvoluted into $\mathrm{Pt}^{2+}$ and $\mathrm{Pt}^{0}$ species as consistent with observation from others ${ }^{[35]}$ and our previous research. ${ }^{[17]}$ While the B.E. of the $\mathrm{Pt}^{0}$ species $(70.9 \mathrm{eV})$ is slightly shifted compared to $\mathrm{NCN}-\mathrm{CN}_{\mathrm{x}}(71.1 \mathrm{eV})$ and melon $(71.2 \mathrm{eV})$, the $\mathrm{Pt}^{2+}$ species at $71.9 \mathrm{eV}$, which has been assigned in the literature to a $\mathrm{PtO}$ shell around the metallic $\mathrm{Pt},{ }^{[35]}$ is over $0.4 \mathrm{eV}$ shifted to lower B.E. compared to $\mathrm{NCN}-\mathrm{CN}_{\mathrm{x}}(72.3 \mathrm{eV})$ and melon $(72.4 \mathrm{eV})$. Invariance of the $\mathrm{N}_{1 \mathrm{~s}}$ signal at $400.8 \mathrm{eV}$ corresponding to the hydrogen bearing $2^{\circ}$ amine lent confidence that the aforementioned shifts are not calibration errors. The directions of the 
shifts - towards higher B.E. for the carbon nitride and lower B.E. for the $\mathrm{Pt}$ - are in accord with a metal-support interaction (MSI), specifically the donation of electron density from the carbon nitride to the Pt. ${ }^{[36]}$ Given that both the oxygen and the $\mathrm{Pt}^{2+}$ XPS signals are shifted by around the same magnitude but opposite direction, this would suggest that the urea moiety is involved in connecting with the co-catalyst, facilitating charge transfer and thus leading to the significant increase in photocatalytic hydrogen evolution. These XPS results are in fact consistent with previous adsorption studies, which have found that the adsorption of urea onto a Pt surface is accompanied by charge transfer from the adsorbate to the metal surface. ${ }^{[37]}$

Characterization by electron microscopy and diffraction (Figure 6 and Figure S5) showed not only formation of Pt particles with diameter of $2-4 \mathrm{~nm}$, but also that these particles seemingly trace the edge of the platelets. This suggests that the urea- $\mathrm{CN}_{\mathrm{x}}$ contained preferential sites for Pt to coordinate to and to subsequently be reductively photo-deposited from $\mathrm{H}_{2} \mathrm{PtCl}_{6}$. In the absence of more element specific techniques (XAS and electron tomography), our inference consistent with our above ${ }^{15} \mathrm{~N}$ NMR and XPS findings as well as literature precedents is that the urea moieties at the periphery are coordinating through the oxygen to the Pt cocatalyst.

As a final indicator, we use electronic structure theory to corroborate the implications derived from the experimental observations above. We note that replicating the precise mechanistic details of the photocatalyst and its operation by first-principles modelling would significantly exceed the capabilities of any first-principles approaches currently available. However, several key open questions that can be addressed relate to how the interaction with the Pt cocatalyst differs between differently functionalized substrates, particularly melon and urea$\mathrm{CN}_{\mathrm{x}}$. These questions include: 1) the extent of the support/co-catalyst interaction; 2) the 
moieties involved in the coordination to the Pt cluster; and 3) the potential for electron versus hole transfer to the Pt cluster. Below, we approach these questions using still demanding, yet feasible, ground state density-functional theory (DFT) based simulations. The findings here aim to elucidate the characteristics that improve the electron transfer to the platinum, which based on the above discussions appears to be the rate limiting step. It does not, however, model the inherent carrier dynamics of the carbon nitrides, such as the processes related to charge carrier separation or the percolation of charges inside the carbon nitride as discussed in the PL section.

Specifically, we address questions 1-3 by comparing the electronic structure of two different computational models of the substrate-Pt interaction, shown in Figure 7: (i) a $\mathrm{Pt}_{13}$ cluster adsorbed on a bilayer of melon (Fig. 7 a and c), and (ii) a $\mathrm{Pt}_{13}$ cluster adsorbed on a conceptual structural model of a bilayer of urea-CN $\mathrm{CN}_{\mathrm{x}}$ (Fig. $7 \mathrm{~b}$ and d). While the structure of melon layers is reasonably well established from past theory and experiment, we do not, at this point, know the precise atomic structure of urea- $\mathrm{CN}_{\mathrm{x}}$ planes. In order to facilitate a meaningful comparison between both substrates, we therefore choose a computational structure model for the urea- $\mathrm{CN}_{\mathrm{x}}$ structure that allows us to focus specifically on the differences that arise from replacing the $\mathrm{NH}_{2}$ side chains of melon with the $\mathrm{NH}-\mathrm{CO}-\mathrm{NH}_{2}$ side chains of urea- $\mathrm{CN}_{\mathrm{x}}$. The chosen model substrate geometry of urea- $\mathrm{CN}_{\mathrm{x}}$ is thus as similar as possible to melon, i.e., a hydrogen-bonded bilayer model of $1 \mathrm{D}$ heptazine polymer strands, but with all $\mathrm{NH}_{2}$ groups replaced by urea moieties (see Scheme $\mathrm{S} 1$, bottom left). Both structure models are realized as periodically repeated supercells. The unit cell dimension perpendicular to the bilayers ( $z$ direction) is $40 \AA$, ensuring a large vacuum region. Additionally, we employ a dipole correction ${ }^{[38]}$ in the $z$ direction to prevent interactions between different periodic images. The periodic images of the adsorbed $\mathrm{Pt}_{13}$ clusters are 
separated by using lateral supercell dimensions of four parallel heptazine strands with six heptazine units along each strand in each layer. For the initial geometry of $\mathrm{Pt}_{13}$, we chose a minimum-energy structure determined by Piotrowski et al.$^{[39]}$ The full bilayer models including the $\mathrm{Pt}_{13}$ cluster comprise a total of 877 atoms for melon and 1,069 atoms for urea$\mathrm{CN}_{\mathrm{x}}$. All atomic positions and lateral unit cell parameters were fully relaxed to the nearest local minima of the potential-energy surface. The urea- $\mathrm{CN}_{\mathrm{x}}$ model analyzed in Figure $7 \mathrm{~b}$ and $\mathrm{d}$ is the lowest-energy model out of three different cluster-bilayer models that we tested for urea-CN $\mathrm{CN}_{\mathrm{x}}$, all of which included the attachment of $\mathrm{Pt}_{13}$ to $\mathrm{O}$ as an important feature. All calculations were performed using the FHI-aims all-electron electronic structure code ${ }^{[40]}$, "light" settings and the $\Gamma$ point for Brillouin zone integration, and the Perdew-BurkeErnzerhof $(\mathrm{PBE})^{[41]}$ density functional together with the Tkatchenko-Scheffler pairwise van der Waals dispersion correction ${ }^{[42]}(\mathrm{PBE}+\mathrm{vdW})$.

In Figure 7a) and b), we show the element-resolved partial densities of states of $\mathrm{Pt}_{13}$ adsorbed at the melon bilayer vs. at the urea- $\mathrm{CN}_{\mathrm{x}}$ bilayer, respectively. We note that, without adsorbed $\mathrm{Pt}_{13}$ and in DFT-PBE, the melon bilayer would have a HOMO-LUMO gap of $2.53 \mathrm{eV}$, whereas the Pt-free urea-CN $\mathrm{C}_{\mathrm{x}}$ bilayer would have a smaller HOMO-LUMO gap of $2.25 \mathrm{eV}$; these values are consistent with the C-N band edges inferred from Figs. 7a) and b) when $\mathrm{Pt}_{13}$ is present. Insets in both figures show the fully relaxed local $\mathrm{Pt}_{13}$ adsorption geometry at either substrate. Furthermore, the complete model geometries used for melon and urea- $\mathrm{CN}_{\mathrm{x}}$ are also shown in Figure 7c) and 7d), respectively, together with the orbital densities of two particular hybridized states close to (at or just below) the substrate LUMO levels (see below). Coming to the geometries first (provided in the NoMaD repository), the melon bilayer, which has strong hydrogen bonding within the plane, shows comparatively little structural rearrangement as a result of $\mathrm{Pt}_{13}$ adsorption. Here, the $\mathrm{Pt}_{13}$ cluster shifts to connect to one of 
the $\mathrm{NH}_{2}$ functionalities, which is slightly pulled out of the plane. In contrast, the urea- $\mathrm{CN}_{\mathrm{x}}$ bilayer model displays a substantial rearrangement of its atomic positions. In line with the experimental conclusions, there is a direct attachment of $\mathrm{Pt}_{13}$ to the $\mathrm{O}$ functionality of urea, as well as a connection to several of the $\mathrm{N}$ atoms of different adjacent heptazine rings. We also estimated the overall charge transfer from the substrates to the neutral $\mathrm{Pt}_{13}$ cluster by Mulliken and Hirshfeld ${ }^{[43]}$ atoms-in-molecules partitioning schemes. Both schemes indicate practically no charge transfer from melon to $\mathrm{Pt}_{13}$ (Mulliken: $-0.18 \mathrm{e}$, Hirshfeld: $0.0 \mathrm{e}$ ), and a small transfer of electrons to $\mathrm{Pt}_{13}$ (Mulliken: $-0.571 \mathrm{e}$, Hirshfeld: $-0.15 \mathrm{e}$ ) for our particular urea- $\mathrm{CN}_{\mathrm{x}}-\mathrm{Pt}_{13}$ model.

We next turn to a closer analysis of the hybridization of $\mathrm{Pt}_{13}$ states with the near-edge carrier states of the substrates. Since the $\mathrm{Pt}_{13}$ cluster is finite, the energies of its states found in the band gaps of melon and urea- $\mathrm{CN}_{\mathrm{x}}$ are discrete. We can therefore analyze the character of each state near and in-between the substrate band edges by performing a Mulliken decomposition into contributions from the $\mathrm{Pt}_{13}$ cluster and contributions from the substrates. The result of the state-resolved Mulliken analysis is shown in the bottom panels of Figures 7a and c. For comparison, we also visualize the orbitals associated with all states close to or inbetween the band edges of $\mathrm{Pt}_{13}-$ melon and of $\mathrm{Pt}_{13}-\mathrm{urea}-\mathrm{CN}_{\mathrm{x}}$ in the SI (Figure $\mathrm{S} 8-\mathrm{S} 13$ ). The individual states are labelled by consecutive integer numbers. The number zero indicates the state closest to the Fermi level, here taken to be the highest-energy state with an electronic occupation greater than 0.5 . Negative labels indicate filled states and positive numbers indicate empty states. Based on the Mulliken analyses, we assign the state labelled " -26 " in the lower panel of Figure 7a) to the valence band maximum (VBM/HOMO) of melon. The state labelled "6" in Figure 7a) is assigned to the conduction band minimum (CBM/LUMO) of melon. Similarly, the states labelled " -34 " and "1" in Figure 7b) are assigned as the 
VBM/HOMO and CBM/LUMO of the urea- $\mathrm{CN}_{\mathrm{x}}$ bilayer, respectively. However, states 2-4 are very close to state 1 in energy and are predominantly $\mathrm{CN}_{\mathrm{x}}$ derived as well. They are thus likely to be closely associated with the CBM/LUMO as well.

The discrete states in the band gaps of melon and of urea- $\mathrm{CN}_{\mathrm{x}}$ are almost purely $\mathrm{Pt}_{13}$-derived. However, a few states near the band edges show a greater degree of hybridization. Let us first analyze the electron-like states near the CBMs/LUMOs. For melon- $\mathrm{Pt}_{13}$, a particular state of interest is the partially hybridized state 5 , just $0.2 \mathrm{eV}$ below the apparent LUMO of melon. The orbital density of this state is shown in Figure 7c). State 5 is strongly localized near the $\mathrm{Pt}_{13}$ cluster, but extends to a few heptazine units of the substrate. This or similar hybridized states associated with the $\mathrm{NH}_{2}$ moieties of melon could well serve as the states that facilitate electron transfer to the Pt co-catalyst in general. The case of urea- $\mathrm{CN}_{\mathrm{x}}$ is strikingly different in that the states derived from its LUMO (just above the highest occupied level of the Pt cluster) appear to be significantly more hybridized with the Pt states. As an example, Figure 7d) shows the orbital density for state 1 in the lower panel of Figure 7b), which is much more extended along the strands near the Pt cluster than is the case for state 5 of Fig. $7 \mathrm{c}$ ) (melon). Assuming that these hybridized states can be viewed as indicative of electron transfer pathways to the Pt cluster, the comparison indeed suggests that the electron transfer could be more effective in the presence of urea functionalities than for the unmodified melon.

Regarding the states near the substrate VBMs/HOMOs, we observe that state -26 , the HOMO of melon, is not appreciably hybridized with the $\mathrm{Pt}_{13}$ cluster, but several other states just above it show some hybridization. In contrast, our urea- $\mathrm{CN}_{\mathrm{x}}-\mathrm{Pt}_{13}$ model shows no significant hybridization of the Pt-derived states with the HOMO, i.e., with the potential holelike states. 
In summary, the results from our DFT-PBE+vdW model calculations are supportive of key observations relating to the Pt-substrate interaction, specifically of an overall stronger metalsupport interaction for urea- $\mathrm{CN}_{\mathrm{x}}$, facilitated via $\mathrm{O}$ moieties, and of a stronger hybridization of the electron-like states of urea- $\mathrm{CN}_{\mathrm{x}}$ with Pt-derived states. The latter could be indicative of more facile electron transfer pathways available in urea- $\mathrm{CN}_{\mathrm{x}}$ than in the archetype melon.

Collectively, our results above may provide a retrodictive explanation to the observation that melon prepared from urea, rather than from dicyandiamide or melamine, performed better photocatalytically. ${ }^{[20]}$ The literature rationales for this observation have been attributed to increased surface area ${ }^{[20 a]}$ or increased condensation in the carbon nitride. ${ }^{[20 b]}$ While the former certainly contributes to the increased activity, Martin et al. have argued it does not sufficiently account for the vast improvement observed. ${ }^{[20 b]}$ Indeed, our results infer that the higher activity observed in melon prepared from urea (henceforth notated as melon (urea))as compared to that from melamine is attributable to residual functional groups, namely the urea moiety, from the incomplete cyclization and condensation of urea to heptazine via dicyandiamide and melamine. For example, oxygen can be incorporated from ureidomelamine, ${ }^{[44]}$ an impurity in melamine, or from trace water and oxygen in the synthesis atmosphere. To verify our retrodiction, we prepared a sample of melon from urea for comparison of the characterization results (Figure 8). As predicted, a small but nonetheless discernible urea signal is observed in the ${ }^{1} \mathrm{H}_{-}{ }^{15} \mathrm{~N}$ CP NMR at around $-290 \mathrm{ppm}$ for melon (urea), which is absent for melon, and coincides with the urea $\mathrm{NH}_{2}$ signal (N4) for urea- $\mathrm{CN}_{\mathrm{x}}$. Furthermore, the spectra for melon (urea) resemble urea- $\mathrm{CN}_{\mathrm{x}}$ more than those for melon, particularly the apparent downfield shifts for the NMR signals of the heptazine core (N1 and $\mathrm{C} 2 ; \mathrm{N} 3$ to a lesser extent). 
In agreement with previous literature, we found that melon (urea), despite absorbing less in the visible region as evident in their UV-Vis spectra (Figure 8c), performs better for photocatalytic hydrogen evolution than melon: $4.4 v s 1.8 \mu \mathrm{mol} \mathrm{h}^{-1}$ averaged over the first $8 \mathrm{~h}$ under AM1.5 irradiation and $4.7 \%$ vs $0.5 \% \mathrm{AQE}$ at $400 \mathrm{~nm}$. We emphasize that these values are still much lower than that of urea-CN $\mathrm{Cr}_{\mathrm{x}} \mathrm{NCN}-\mathrm{CN}_{\mathrm{x}}\left(56.2 \mu \mathrm{mol} \mathrm{h}^{-1}\right.$ and $24.7 \mu \mathrm{mol} \mathrm{h}{ }^{-1}$, respectively). Through additional characterizations, we rule out as the principal factors for the outperformance of urea- $\mathrm{CN}_{\mathrm{x}}$ the variations in 1) BET surface area, 2) dispersibility in water as measured by zeta potential, 3) Pt loading, and 4) Pt size, morphology and distribution (see supporting information for detailed discussions). From this, we deduce that efficient charge transfer mediated by the platinum/urea- $\mathrm{CN}_{\mathrm{x}}$ interaction seems to be a key determinant for its high activity. This work thus highlights the success of our "defect engineering" strategy by the rational insertion of the activity-promoting functional group into the carbon nitride backbone.

\section{Conclusion}

Treating melon in a KSCN melt followed by acid hydrolysis yielded a carbon nitride polymer decorated with the urea functional group. This urea- $\mathrm{CN}_{\mathrm{x}}$ exhibited one of the highest photocatalytic activities for hydrogen evolution reported for carbon nitrides thus far, with rates over twice that of the $\mathrm{NCN}-\mathrm{CN}_{\mathrm{x}}$ and over 28 times that of melon under simulated sunlight using methanol as the electron donor. Likewise, the apparent quantum efficiency at $400 \mathrm{~nm}$ of this urea-CN $\mathrm{CN}_{\mathrm{x}}(17.9 \%)$ is nearly twice that of $\mathrm{NCN}-\mathrm{CN}_{\mathrm{x}}(9.3 \%)$ and nearly 36 times that of melon $(0.5 \%)$. We attribute this large improvement in activity primarily to the rational insertion of the urea moiety which appears to be the preferential docking site for the platinum co-catalyst and facilitate transfer of photo-generated charges into the hydrogen evolving centers, based on results from TEM, XPS and computational modelling. Following 
these results, we suggest a retrodictive explanation to the better photocatalytic performance of melon prepared from urea compared to those from melamine and dicyandiamide. This rationale was subsequently supported by experimental evidences and for the first time sheds light on the role and nature of oxygen-containing catalytically relevant sites in carbon nitride photocatalysts. Specifically, residual urea groups from incomplete heptazine cyclization and decomposition were found in melon prepared from urea, which are not in detectable abundance in the melon samples from melamine. The strategy presented herein can be considered as an example of "functional defect design" or engineering of catalytically relevant sites, where we deliberately inserted the photocatalytically relevant defect. The vast increase in activity of this engineered sample attests to the success of this strategy which, based on extensive characterization of the urea- $\mathrm{CN}_{\mathrm{x}}$, appears to be an even more promising research direction for improving photocatalytic activity than red-shifting the absorption onset or increasing the surface area, as it can subsequently be combined with all of these latter strategies. Further exploration of mechanistic aspects, as well as exploring other defects native or non-native to melon, may thus provide the design criteria for highly efficient heptazine-based photocatalysts not only for the hydrogen evolution reaction, but also other photoreactions demonstrated to be feasible for this material such as water oxidation, $\mathrm{CO}_{2}$ reduction, and organic transformations.

\section{Experimental Section}

Details of the syntheses and characterization techniques are provided in the supporting information. Computational results are provided in the NoMaD repository under the link http://dx.doi.org/10.17172/NOMAD/2016.11.14-1; computationally calculated structures are also uploaded in the supporting information as cif.

\section{Supporting Information}


Supporting Information is available from the Wiley Online Library or from the author.

\section{Acknowledgements}

V.W.-h.L. gratefully acknowledges a postdoctoral scholarship from the Max Planck Society. This work was supported by the Deutsche Forschungsgemeinschaft (project LO1801/1-1), the Max Planck Society, the cluster of excellence Nanosystems Initiative Munich (NIM), and the Center for Nanoscience (CeNS). Support from a seed grant by the Duke University Energy Initiative is gratefully acknowledged The authors would like to thank Ms. Marie-Luise Schreiber for the elemental analyses, Dr. Mitsuharu Konuma for the XPS analyses, and Mr. Olaf Alberto von Mankowski for the argon sorption measurements.

Received: ((will be filled in by the editorial staff))

Revised: ((will be filled in by the editorial staff)) Published online: ((will be filled in by the editorial staff))

References

[1] J. Xing, W. Q. Fang, H. J. Zhao, H. G. Yang, Chem. Asian J. 2012, 7, 642-657.

[2] A. Fujishima, K. Honda, Nature 1972, 238, 37-38.

[3] a) B. V. Lotsch, M. Döblinger, J. Sehnert, L. Seyfarth, J. Senker, O. Oeckler, W.

Schnick, Chem. Eur. J. 2007, 13, 4969-4980; b) K. Maeda, X. Wang, Y. Nishihara, D. Lu, M. Antonietti, K. Domen, J. Phys. Chem. C 2009, 113, 4940-4947; c) X. Wang, K. Maeda, A.

Thomas, K. Takanabe, G. Xin, J. M. Carlsson, K. Domen, M. Antonietti, Nat. Mater. 2009, 8, 76-80; d) S. Cao, J. Yu, J. Phys. Chem. Lett. 2014, 5, 2101-2107; e) J. Liu, H. Wang, M. Antonietti, Chem. Soc. Rev. 2016, 45, 2308-2326.

Phys. 2010, 12, 2227-2237; b) T. Tyborski, C. Merschjann, S. Orthmann, F. Yang, M.-C. Lux-Steiner, T. Schedel-Niedrig, J. Phys. Condens. Matter 2013, 25, 395402; c) F. Fina, S. K. Callear, G. M. Carins, J. T. S. Irvine, Chem. Mater. 2015, 27, 2612-2618. a) D. M. Teter, R. J. Hemley, Science 1996, 271, 53-55; b) E. Kroke, M. Schwarz, E.

Horath-Bordon, P. Kroll, B. Noll, A. D. Norman, New J. Chem. 2002, 26, 508-512.

[6] M. Döblinger, B. V. Lotsch, J. Wack, J. Thun, J. Senker, W. Schnick, Chem. Commun. 2009, 1541-1543. 
[7] a) B. V. Lotsch, W. Schnick, Chem. Mater. 2006, 18, 1891-1900; b) A. Schwarzer, T. Saplinova, E. Kroke, Coord. Chem. Rev. 2013, 257, 2032-2062; c) B. V. Lotsch, W. Schnick, New J. Chem. 2004, 28, 1129-1136.

[8] C. Butchosa, P. Guiglion, M. A. Zwijnenburg, J. Phys. Chem. C 2014, 118, 2483324842.

[9] a) G. Liu, P. Niu, C. Sun, S. C. Smith, Z. Chen, G. Q. M. Lu, H.-M. Cheng, J. Am. Chem. Soc. 2010, 132, 11642-11648; b) Y. Wang, Y. Di, M. Antonietti, H. Li, X. Chen, X. Wang, Chem. Mater. 2010, 22, 5119-5121; c) J. Zhang, X. Chen, K. Takanabe, K. Maeda, K. Domen, J. D. Epping, X. Fu, M. Antonietti, X. Wang, Angew. Chem. Int. Ed. 2010, 49, 441444; d) Y. Zhang, T. Mori, J. Ye, M. Antonietti, J. Am. Chem. Soc. 2010, 132, 6294-6295; e) J. Zhang, G. Zhang, X. Chen, S. Lin, L. Möhlmann, G. Dołęga, G. Lipner, M. Antonietti, S. Blechert, X. Wang, Angew. Chem. Int. Ed. 2012, 51, 3183-3187; f) Z. Lin, X. Wang, Angew. Chem. Int. Ed. 2013, 52, 1735-1738; g) K. Schwinghammer, B. Tuffy, M. B. Mesch, E. Wirnhier, C. Martineau, F. Taulelle, W. Schnick, J. Senker, B. V. Lotsch, Angew. Chem. Int. Ed. 2013, 52, 2435-2439.

[10] a) X. Chen, Y.-S. Jun, K. Takanabe, K. Maeda, K. Domen, X. Fu, M. Antonietti, X. Wang, Chem. Mater. 2009, 21, 4093-4095; b) P. Niu, L. Zhang, G. Liu, H.-M. Cheng, Adv. Func. Mater. 2012, 22, 2763-4770; c) J. Sun, J. Zhang, M. Zhang, M. Antonietti, X. Fu, X. Wang, Nat. Commun. 2012, 3, 1139; d) X. Wang, K. Maeda, X. Chen, K. Takanabe, K. Domen, Y. Hou, X. Fu, M. Antonietti, J. Am. Chem. Soc. 2009, 131, 1680-1681.

[11] Z. Zhao, Y. Sun, F. Dong, Nanoscale 2015, 7, 15-37.

[12] A. Vojvodic, J. K. Nørskov, Natl. Sci. Rev. 2015, 2, 140-149.

[13] P. V. Kamat, J. Phys. Chem. Lett. 2012, 3, 663-672.

[14] C. Harris, P. V. Kamat, ACS Nano 2010, 4, 7321-7330. 
[15] a) J. Dong, M. Wang, X. Li, L. Chen, Y. He, L. Sun, ChemSusChem 2012, 5, 2133 -

2138; b) S.-W. Cao, X.-F. Liu, Y.-P. Yuan, Z.-Y. Zhang, J. Fang, S. C. J. Loo, J. Barber, T. C.

Sum, C. Xue, Phys. Chem. Chem. Phys. 2013, 15, 18363-18366; c) J. Hong, Y. Wang, Y.

Wang, W. Zhang, R. Xu, ChemSusChem 2013, 6, 2263-2268; d) S.-W. Cao, Y.-P. Yuan, J.

Barber, S. C. J. Loo, C. Xue, Appl. Surf. Sci. 2014, 319, 344-349; e) C. A. Caputo, M. A.

Gross, V. W. Lau, C. Cavazza, B. V. Lotsch, E. Reisner, Angew. Chem. Int. Ed. 2014, 53,

11538-11542; f) H. Kasap, C. A. Caputo, B. C. M. Martindale, R. Godin, V. W.-H. Lau, B. V.

Lotsch, J. R. Durrant, E. Reisner, J. Am. Chem. Soc. 2016, 138, 9183-9192.

[16] V. W.-h. Lau, M. B. Mesch, V. Duppel, V. Blum, J. Senker, B. V. Lotsch, J. Am.

Chem. Soc. 2015, 137, 1064-1072.

[17] V. W.-h. Lau, I. Moudrakovski, T. Botari, S. Weinberger, M. B. Mesch, V. Duppel, J. Senker, V. Blum, B. V. Lotsch, Nat. Commun. 2016, 7, 12165.

[18] Y. Wang, X. Wang, M. Antonietti, Angew. Chem. Int. Ed. 2012, 51, 68-89.

[19] a) T. Güthner, B. Mertschenk, in Ullmann's Encyclopedia of Industrial Chemistry,

2006; b) M. L. Kilpatrick, J. Am. Chem. Soc. 1947, 69, 40-46.

[20] a) Y. Zhang, J. Liu, G. Wu, W. Chen, Nanoscale 2012, 4, 5300-5303; b) D. J. Martin, K. Qiu, S. A. Shevlin, A. D. Handoko, X. Chen, Z. Guo, J. Tang, Angew. Chem. 2014, 53, $9240-9245$.

[21] a) J. Liu, Y. Liu, N. Liu, Y. Han, X. Zhang, H. Huang, Y. Lifshitz, S.-T. Lee, J. Zhong, Z. Kang, Science 2015, 347, 970-974; b) G. Zhang, Z.-A. Lan, L. Lin, S. Lin, X. Wang, Chem. Sci. 2016, 7, 3062-3066.

[22] T. Maschmeyer, M. Che, Angew. Chem. Int. Ed. 2010, 49, 1536-1539.

[23] a) A. Salinaro, A. V. Emeline, J. Zhao, H. Hidaka, V. K. Ryabchuk, N. Serpone, Pure Appl. Chem. 1999, 71, 321-335; b) N. Serpone, A. Salinaro, Pure Appl. Chem. 1999, 71, 303320. 
[24] H. Kisch, D. Bahnemann, J. Phys. Chem. Lett. 2015, 6, 1907-1910.

[25] M. J. Berr, P. Wagner, S. Fischbach, A. Vaneski, J. Schneider, A. S. Susha, A. L.

Rogach, F. Jäckel, J. Feldmann, Appl. Phys. Lett. 2012, 100, 223903.

[26] S. Horikoshi, N. Watanabe, M. Mukae, H. Hidaka, N. Serpone, New J. Chem. 2001, 25, 999-1005.

[27] F. Guzman, S. S. C. Chuang, C. Yang, Ind. Eng. Chem. Res. 2013, 52, 61-65.

[28] B. Jürgens, E. Irran, J. Senker, P. Kroll, H. Müller, W. Schnick, J. Am. Chem. Soc.

2003, $125,10288-10300$.

[29] T. Komatsu, J. Mater. Chem. 2001, 11, 799-801.

[30] C. Gervais, F. Babonneau, J. Maquet, C. Bonhomme, D. Massiot, E. Framery, M.

Vaultier, Magn. Reson. Chem. 1998, 36, 407-414.

[31] M. Shalom, S. Inal, C. Fettkenhauer, D. Neher, M. Antonietti, J. Am. Chem. Soc. 2013, $135,7118-7121$.

[32] a) D. Hollmann, M. Karnahl, S. Tschierlei, K. Kailasam, M. Schneider, J. r. Radnik, K.

Grabow, U. Bentrup, H. Junge, M. Beller, S. Lochbrunner, A. Thomas, A. Brückner, Chem.

Mater. 2014, 26, 1727-1733; b) H. Zhang, A. Yu, J. Phys. Chem. C 2014, 118, 11628-11635.

[33] a) K. Wu, T. Lian, Chem. Soc. Rev. 2016, 45, 3781-3810; b) T. Simon, N.

Bouchonville, M. J. Berr, A. Vaneski, A. Adrović, D. Volbers, R. Wyrwich, M. Döblinger, A.

S. Susha, A. L. Rogach, F. Jäckel, J. K. Stolarczyk, J. Feldmann, Nat. Mater. 2014, 13, 1013 1018.

[34] A. Thomas, A. Fischer, F. Goettmann, M. Antonietti, J.-O. Müller, R. Schlögl, J. M.

Carlsson, J. Mater. Chem. 2008, 18, 4893-4908.

[35] F. Fina, H. Ménard, J. T. S. Irvine, Phys. Chem. Chem. Phys. 2015, 17, 13929-13936.

[36] a) P. Bera, K. R. Priolkar, A. Gayen, P. R. Sarode, M. S. Hegde, S. Emura, R.

Kumashiro, V. Jayaram, G. N. Subbanna, Chem. Mater. 2003, 15, 2049-2060; b) F. Zhang, J. 
Chen, X. Zhang, W. Gao, R. Jin, N. Guan, Y. Li, Langmuir 2004, 20, 9329-9334; c) Y. Nagai, T. Hirabayashi, K. Dohmae, N. Takagi, T. Minami, H. Shinjoh, S. Matsumoto, J. Catal. 2006, 242, 103-109; d) A. Lewera, L. Timperman, A. Roguska, N. Alonso-Vante, J. Phys. Chem. C 2011, 115, 20153-20159; e) N. G. Akalework, C.-J. Pan, W.-N. Su, J. Rick, M.-C. Tsai, J.-F. Lee, J.-M. Lin, L.-D. Tsaic, B.-J. Hwang, J. Mater. Chem. 2012, 22, 20977-20985.

[37] a) V. Climent, A. Rodes, R. Albalat, J. Claret, J. M. Feliu, A. Aldaz, Langmuir 2001, 17, 8260-8269; b) M. García-Hernández, U. Birkenheuer, A. Hu, F. Illas, N. Rösch, Surf. Sci. 2001, 471, 151-162.

[38] J. Neugebauer, M. Scheffler, Physical review. B, Condensed matter 1992, 46, 1606716080.

[39] M. J. Piotrowski, P. Piquini, J. L. F. Da Silva, Physical Review B 2010, 81, 155446.

[40] a) V. Blum, R. Gehrke, F. Hanke, P. Havu, V. Havu, X. Ren, K. Reuter, M. Scheffler, Comput. Phys. Commun. 2009, 180, 2175-2196; b) V. Havu, V. Blum, P. Havu, M. Scheffler, J. Comput. Phys. 2009, 228, 8367-8379; c) F. Knuth, C. Carbogno, V. Atalla, V. Blum, M. Scheffler, Comput. Phys. Commun. 2015, 190, 33-50; d) A. Marek, V. Blum, R. Johanni, V. Havu, B. Lang, T. Auckenthaler, A. Heinecke, H.-J. Bungartz, H. Lederer, J. Phys. Condens. Matter 2014, 26, 213201.

[41] J. P. Perdew, K. Burke, M. Ernzerhof, Phys. Rev. Lett. 1996, 77, 3865-3868.

[42] A. Tkatchenko, M. Scheffler, Phys. Rev. Lett. 2009, 102, 073005.

[43] F. L. Hirshfeld, Theoretica Chimica Acta 1977, 44, 129-138.

[44] M. Himmelsbach, T. D. T. Vo, Electrophoresis 2014, 35, 1362-1367. 


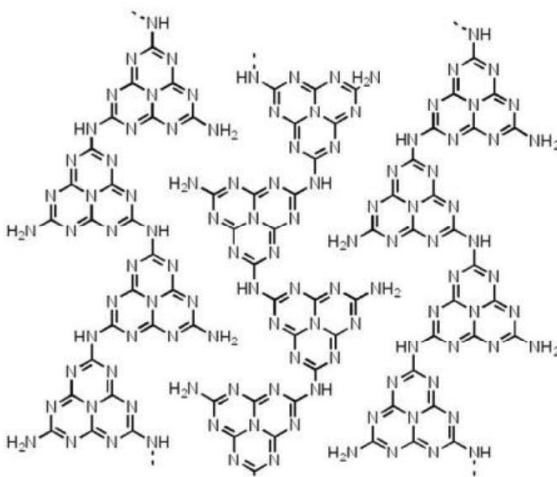

Melon (1D polymer)

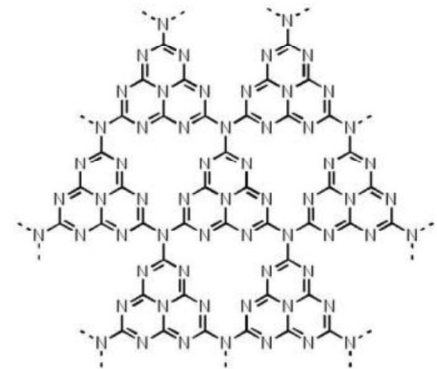

g- $\mathrm{C}_{3} \mathrm{~N}_{4}$

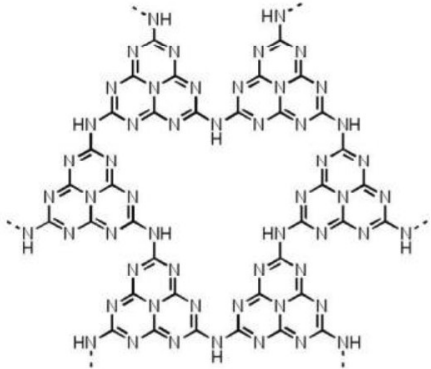

PHI

Scheme 1. Structures of "graphitic carbon nitrides". Shown are the 1D polymer melon (left), the fully condensed 2D counterpart (middle), and the 2D network PHI.

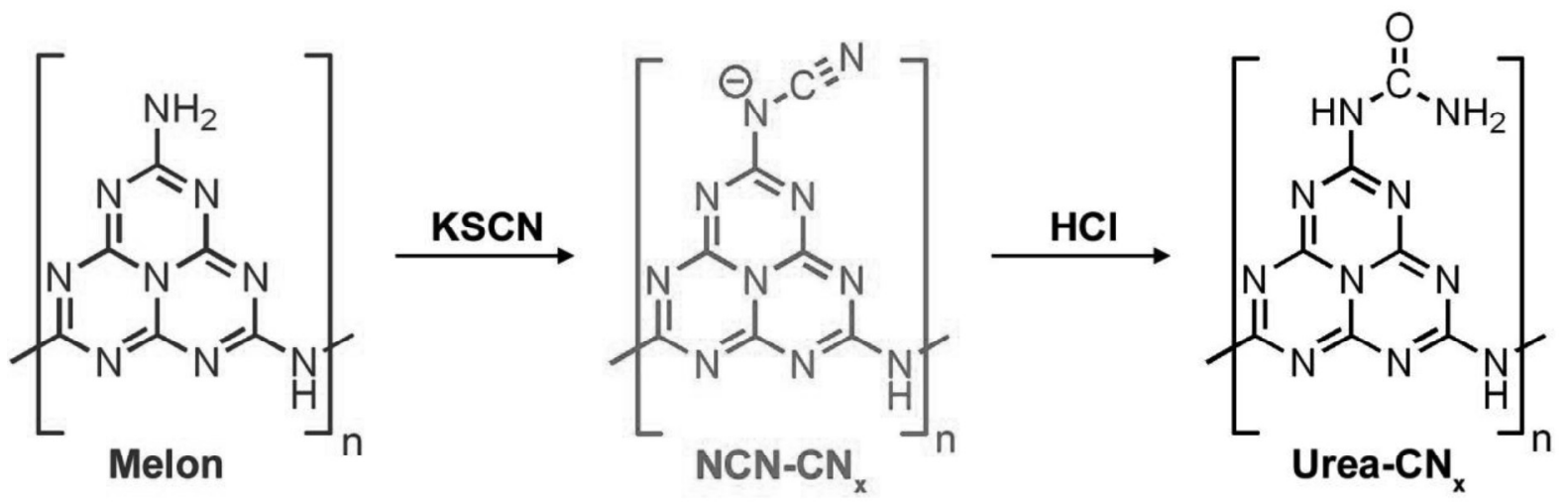

Scheme 2. Simplified reaction scheme of the compound synthesized in this work, showing melon and its conversion to $\mathrm{NCN}_{-} \mathrm{CN}_{\mathrm{x}}$ by a post-synthetic reaction using $\mathrm{KSCN}$ melt, and its acid-induced hydrolysis to urea- $\mathrm{CN}_{\mathrm{x}}$. 

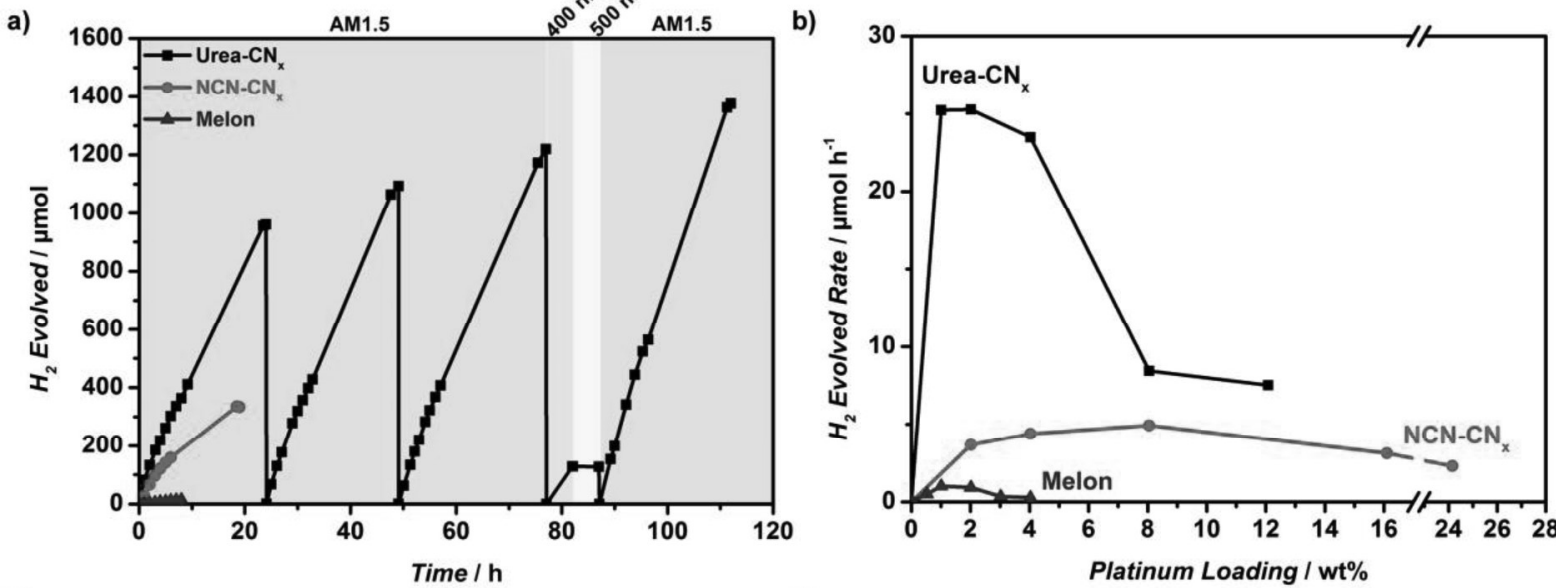

c)

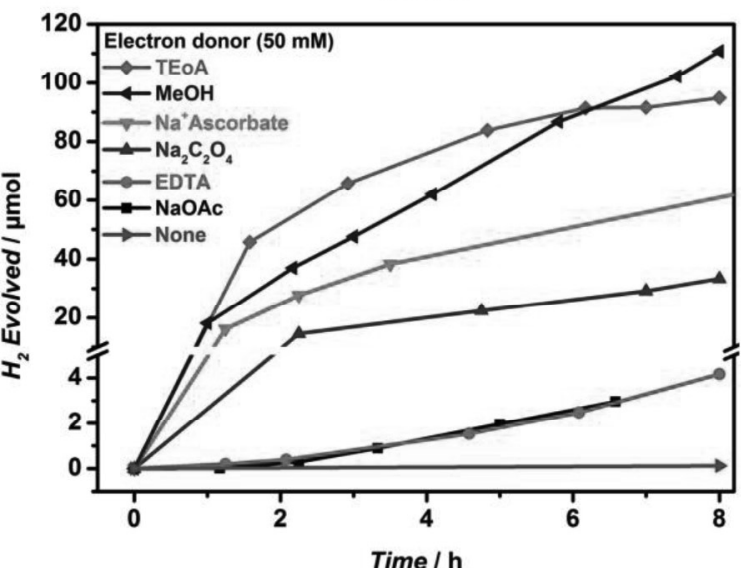

Figure 1. a) Photocatalytic hydrogen evolution under AM1.5, $400 \mathrm{~nm}$ or $500 \mathrm{~nm}$ band pass irradiation using methanol (10 vol\%) as electron donor at the optimized Pt loading. Reactor headspace was purged after every overnight cycle, and methanol $(200 \mu \mathrm{L})$ was added on the $24^{\text {th }}$ and $87^{\text {th }}$ hour. Since the gas chromatograph is operated manually, sampling is done at irregular intervals to give the illusion that the rate is increasing. b) Optimization of hydrogen evolution rate to Pt loading. c) Hydrogen evolution under AM1.5 irradiation and optimized Pt loading using different electron donors $(50 \mathrm{mM})$; note that the non-linearity of some plots are due to the break in the y-axis. d) Photocatalytic hydrogen evolution without Pt co-catalyst under AM1.5 irradiation, using aqueous methanol as electron donor (10 vol\%); note that some plots appear erratic as the amounts of hydrogen evolved were small and may be affected by frequent sampling. 
a)

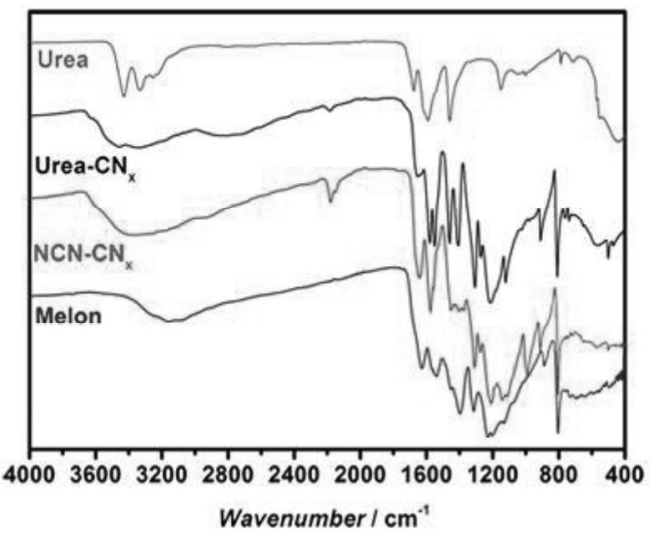

c)

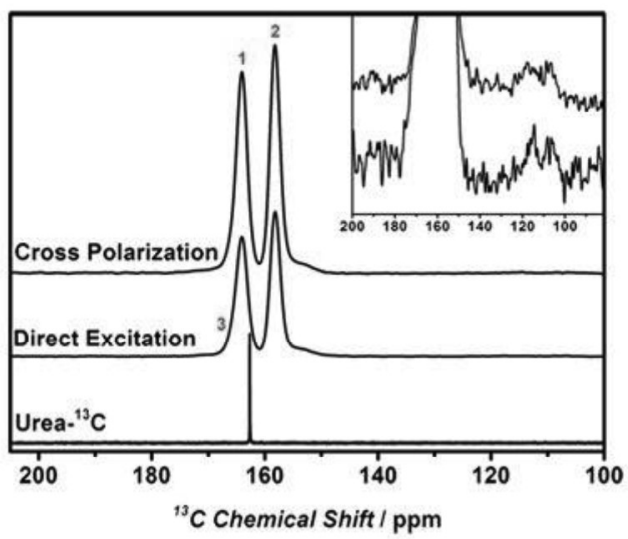

e)

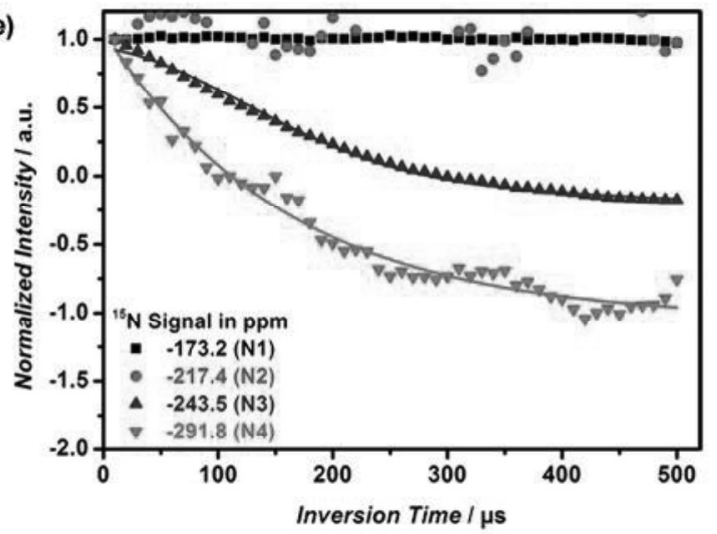

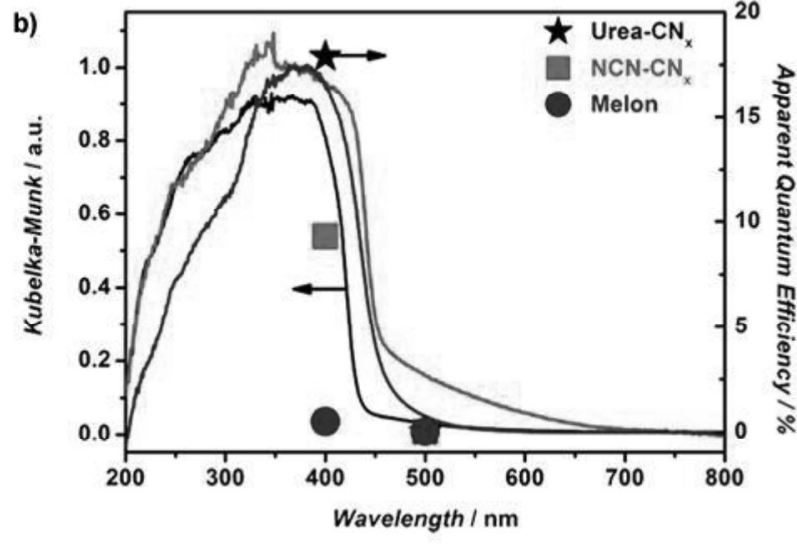

d)
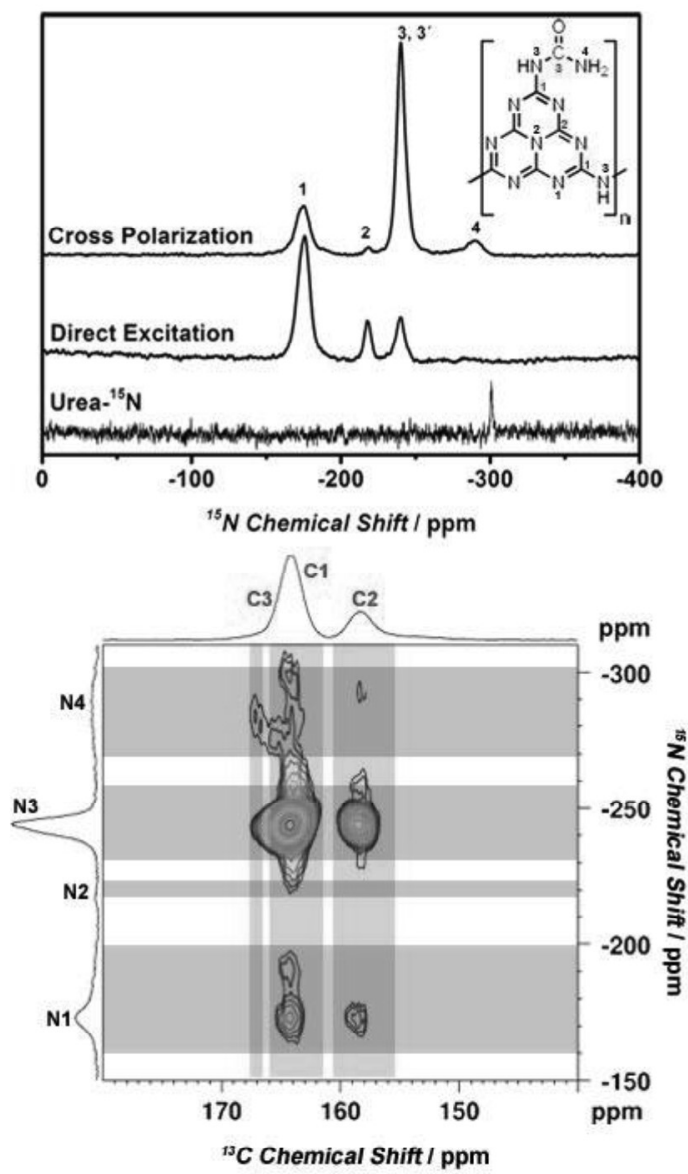

Figure 2. Spectroscopic characterization of urea- $\mathrm{CN}_{\mathrm{x}}$ : a) FTIR (enlarged spectra in the 2400$1400 \mathrm{~cm}^{-1}$ range shown in Figure S2); b) action spectrum compared to those of NCN-CN and melon; c) ${ }^{13} \mathrm{C}$ and d) ${ }^{15} \mathrm{~N}$ magic angle spinning solid state NMR with either ${ }^{1} \mathrm{H}$ cross polarization or direct excitation; inset of $\mathrm{c}$ is an enlarged version showing the minute ${ }^{13} \mathrm{C}$ cyanamide signal, while the inset of $d$ shows the proposed structure of urea- $\mathrm{CN}_{\mathrm{x}}$ and the NMR assignment; e) evolution of signal integrals $v s$ inversion time in the ${ }^{15} \mathrm{~N}$ CPPI experiment and estimation of the turning points, f) ${ }^{15} \mathrm{~N}-{ }^{13} \mathrm{C} 2 \mathrm{D}$ spectrum of the ${ }^{1} \mathrm{H} \rightarrow{ }^{15} \mathrm{~N}$, ${ }^{15} \mathrm{~N} \rightarrow{ }^{13} \mathrm{C}$ double cross polarization experiment. Comparisons of the ${ }^{13} \mathrm{C}$ and ${ }^{15} \mathrm{~N}$ NMR spectra were made with ${ }^{15} \mathrm{~N}$-enriched urea in $\mathrm{D}_{2} \mathrm{O}$. Deconvolution of the $\mathrm{N} 3$ signal in the ${ }^{15} \mathrm{~N}$ CP NMR is shown in Figure S2. 
a)
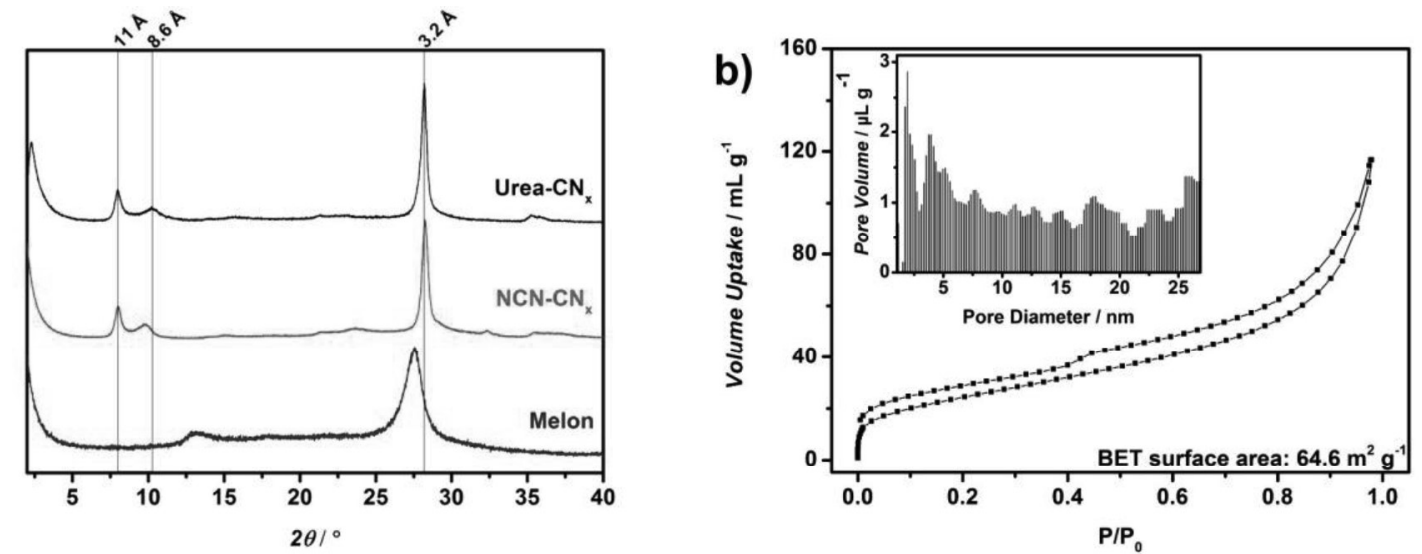

c)

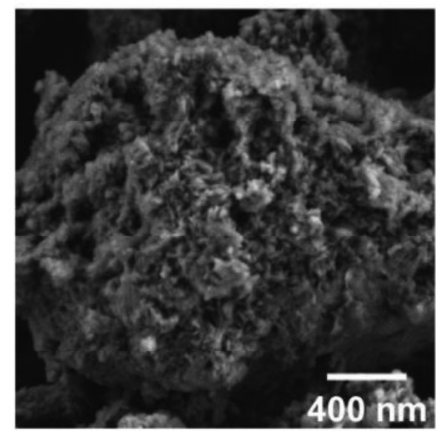

d)

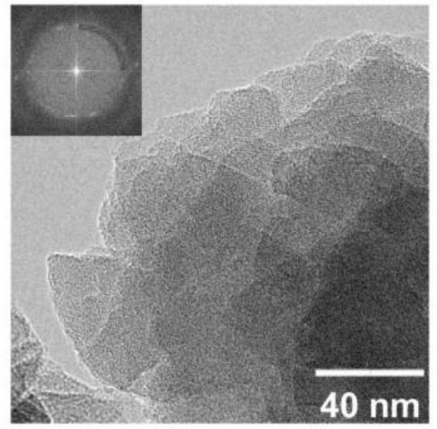

e)

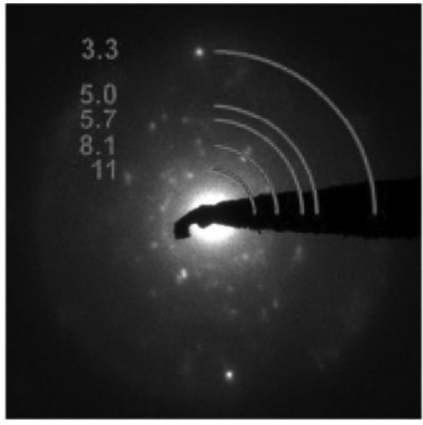

Figure 3. Characterization of urea- $\mathrm{CN}_{\mathrm{x}}$ : a) XRD pattern of urea- $\mathrm{CN}_{\mathrm{x}}$ compared with those of NCN-CN ${ }_{x}$ and melon; b) argon sorption isotherm and pore size distribution (inset); c) SEM; d) TEM and its fast Fourier transform (inset), where the red quarter circle shows a $d$-spacing of $10.4 \AA$, and e) electron diffraction pattern, where the quarter circles show $d$-spacings in $\AA$. 

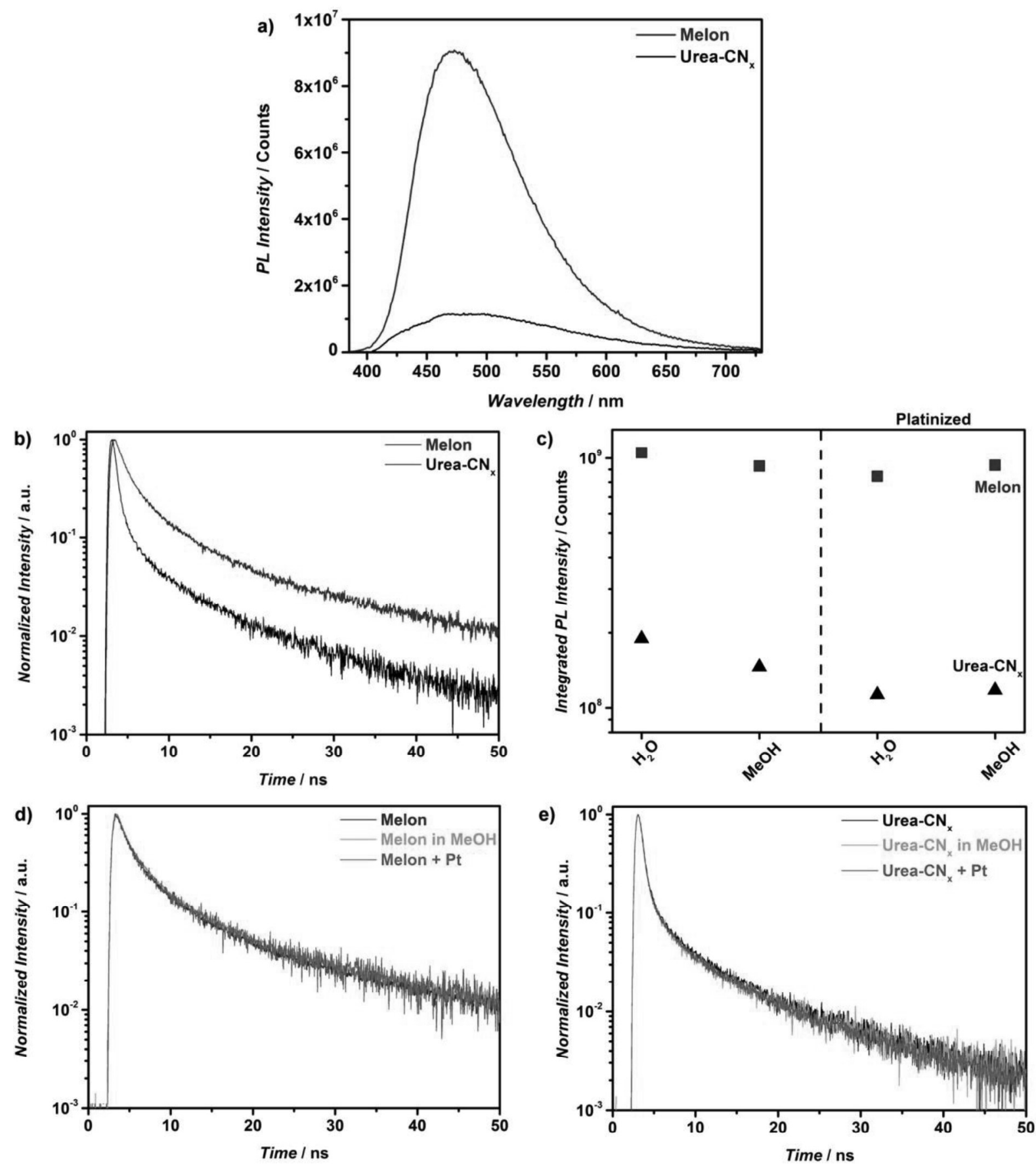

Figure 4. a) PL spectra with excitation at $375 \mathrm{~nm}$ of aqueous suspensions of melon and urea$\mathrm{CN}_{\mathrm{x}}$; b) PL decay curves of melon and urea- $\mathrm{CN}_{\mathrm{x}}$; c) comparison of the PL intensity for melon and urea- $\mathrm{CN}_{\mathrm{x}}$ under different environments based on the integral of the PL signal; comparison of PL decay curves of melon (d) and urea-CN $\mathrm{N}_{\mathrm{x}}(\mathrm{e})$ in the presence of the electron $(\mathrm{Pt})$ or hole acceptor $(\mathrm{MeOH})$. 
a)

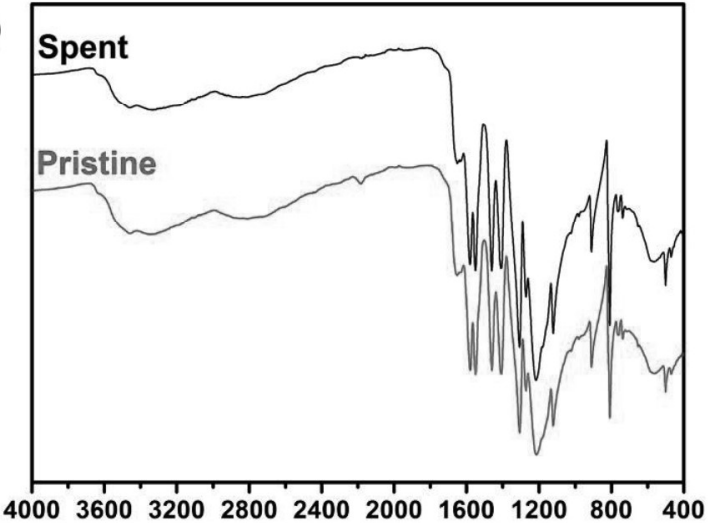

Wavenumber $/ \mathrm{cm}^{-1}$

c)

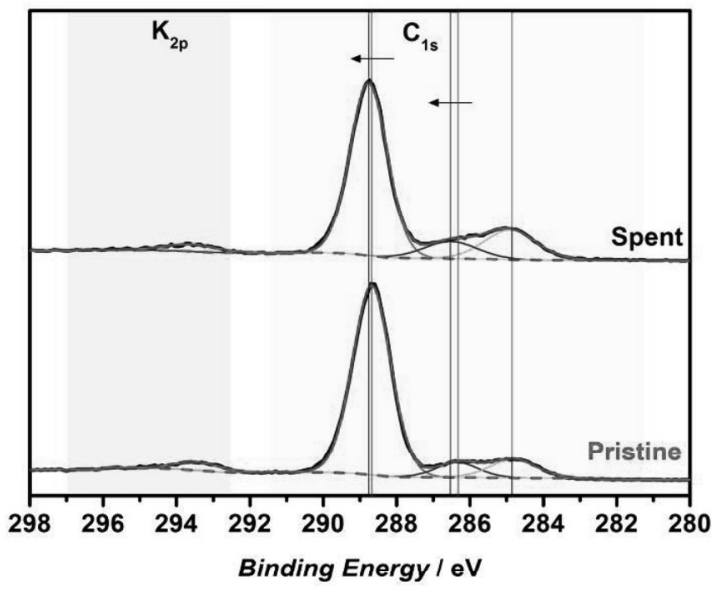

e)

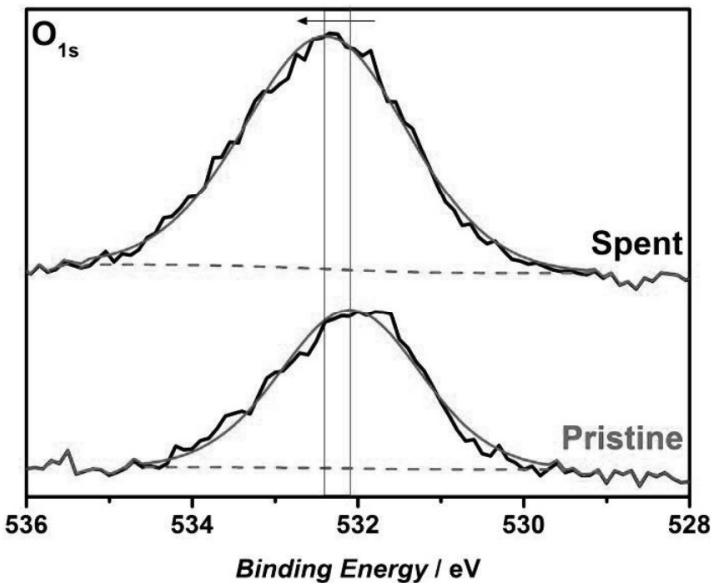

g)

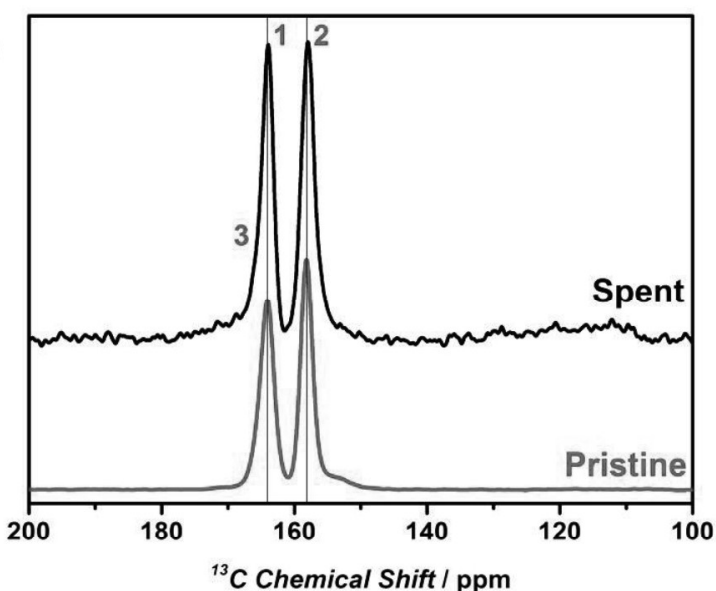

b)

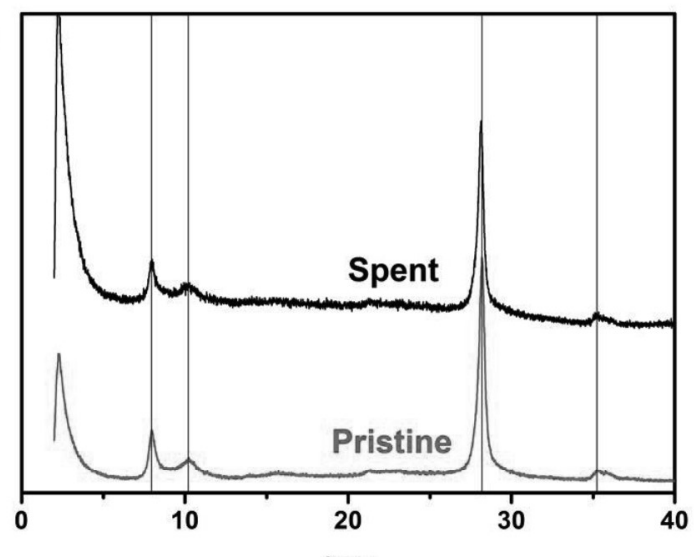

$2 \theta /^{\circ}$

d)

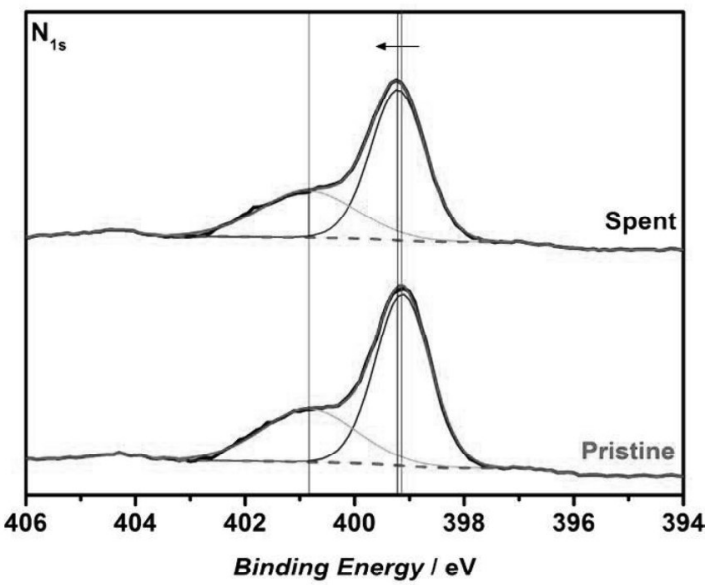

f)

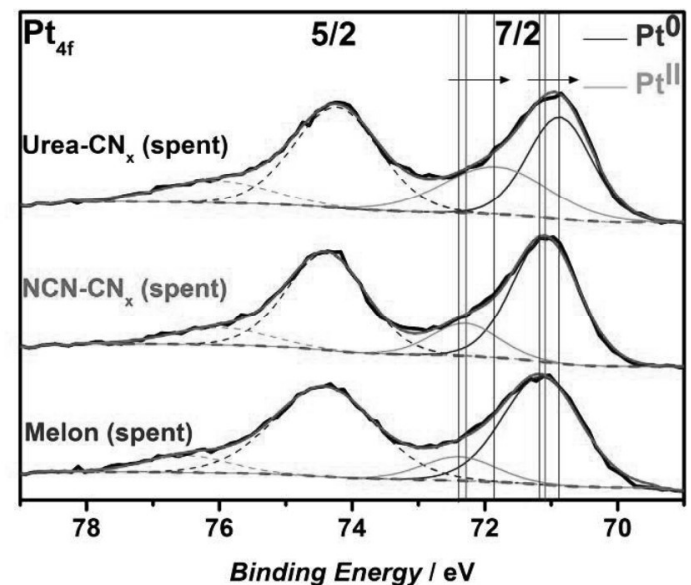

h)

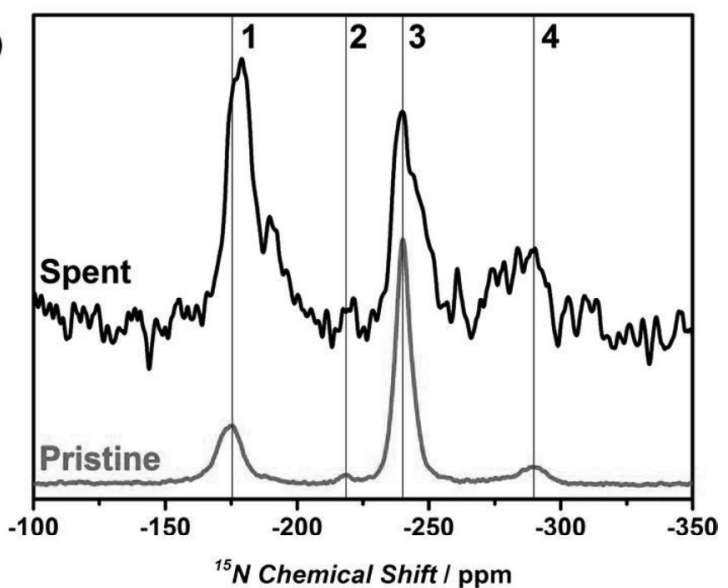


Figure 5. Characterization of the spent photocatalyst compared to the pristine material by: a) FTIR; b) XRD; XPS spectrum referenced to adventitious carbon at $284.8 \mathrm{eV}$ in the $\mathrm{K}_{2 \mathrm{p}}$ and $\mathrm{C}_{1 \mathrm{~s}}(\mathrm{c}), \mathrm{N}_{1 \mathrm{~s}}(\mathrm{~d}), \mathrm{O}_{1 \mathrm{~s}}(\mathrm{e})$ and $\mathrm{Pt}_{4 \mathrm{f}}(\mathrm{f})$ regions. For (c) to (e), the black and red hairlines correspond respectively to the spent and pristine urea- $\mathrm{CN}_{\mathrm{x}}$, while for (f) the black, red and black hairlines correspond to urea-CN $\mathrm{CN}_{\mathrm{x}}, \mathrm{NCN}-\mathrm{CN}_{\mathrm{x}}$ and melon, respectively. For (c) to (e), the direction of the peak(s) shift of the spent compared to the pristine catalyst is indicated by the arrow. For (f), the arrows show the direction of the peak shift going from melon to $\mathrm{NCN}-\mathrm{CN}_{\mathrm{x}}$ to urea-CN $\mathrm{CN}_{\mathrm{x}}{ }^{13} \mathrm{C}$ direct excitation (g), and ${ }^{15} \mathrm{~N} \mathrm{CP}(\mathrm{h})$ MAS ssNMR. Since only changes in the chemical environments, rather than their quantification, are of interest in the NMR spectra, the spent catalyst with natural isotopic abundance is compared with the pristine one from Figure 2, which has $99 \%{ }^{13} \mathrm{C}$ and ${ }^{15} \mathrm{~N}$ isotope enrichment.

a)

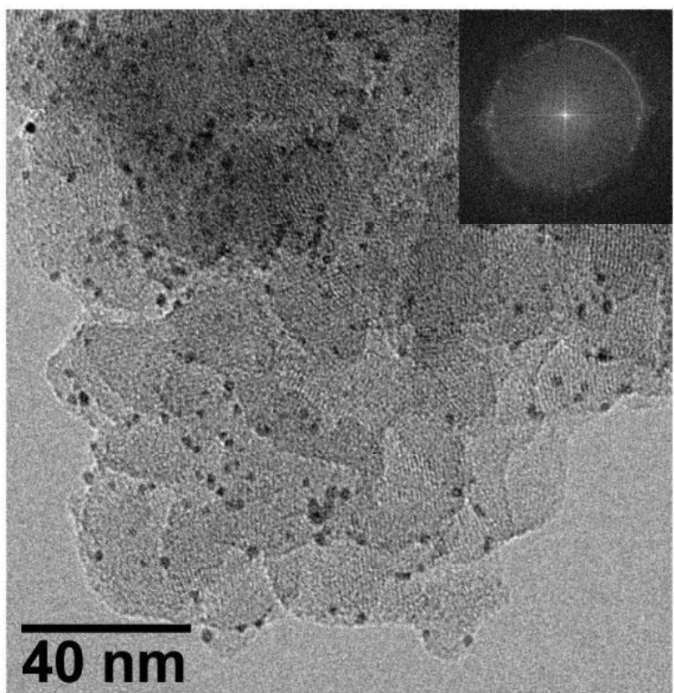

b)

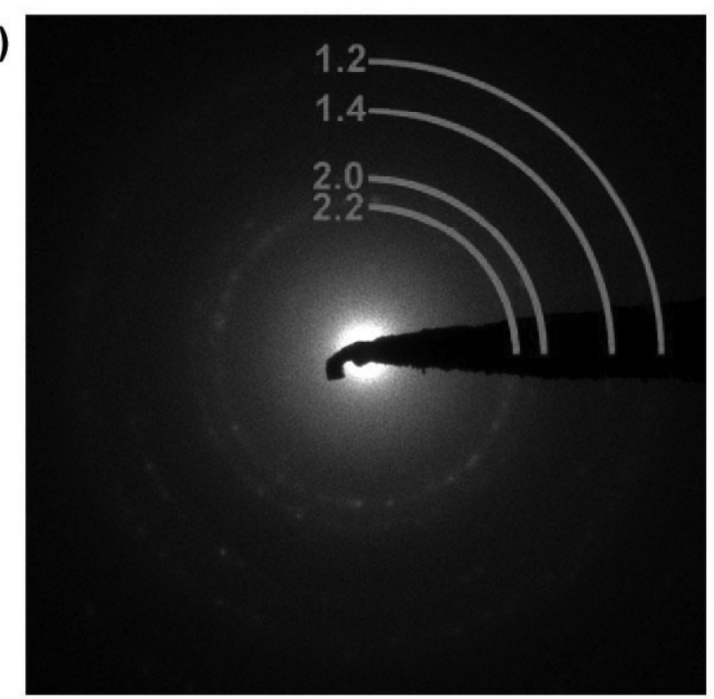

Figure 6. Electron microscopy analyses of the urea- $\mathrm{CN}_{\mathrm{x}}$ after $100+\mathrm{h}$ photocatalysis: a) TEM and the FFT with the quarter circle indicating a $d$-spacing of $11 \AA$ (inset); b) electron diffraction pattern showing the $d$-spacings in $\AA$ of $\mathrm{Pt}$. 
a)
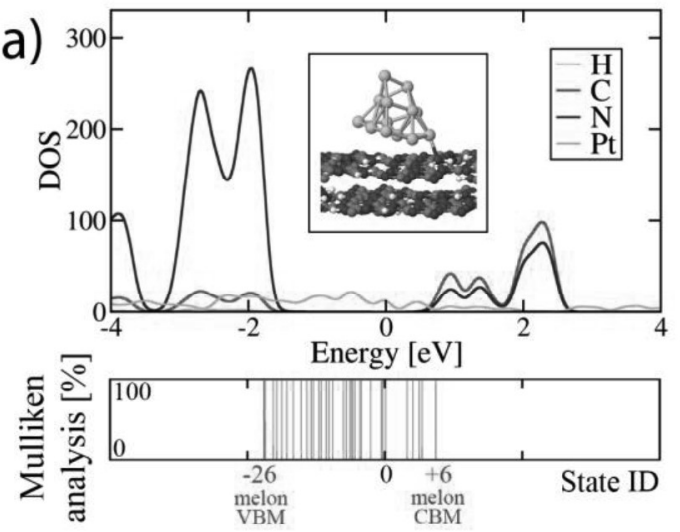

c)
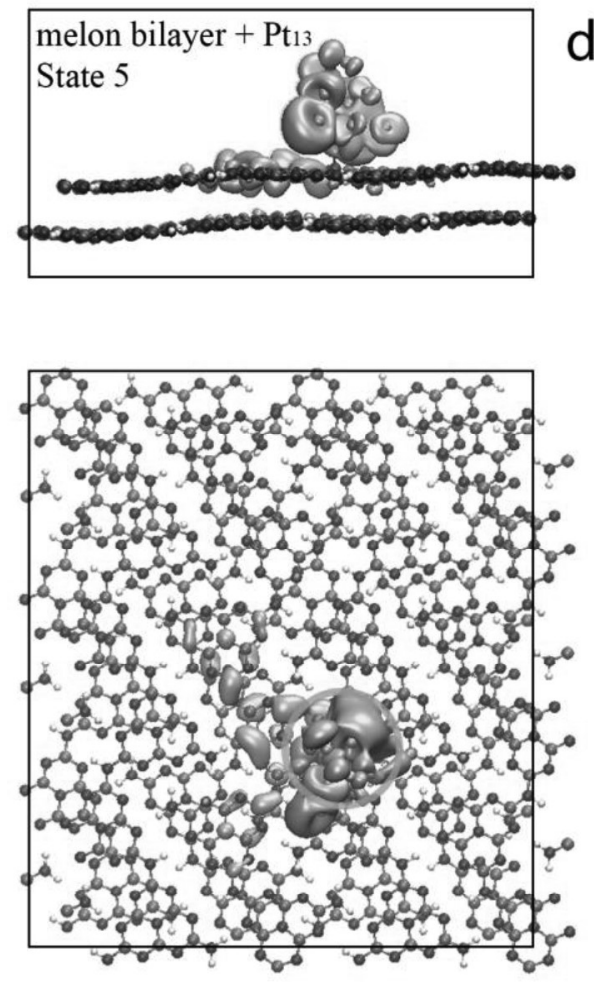

d)

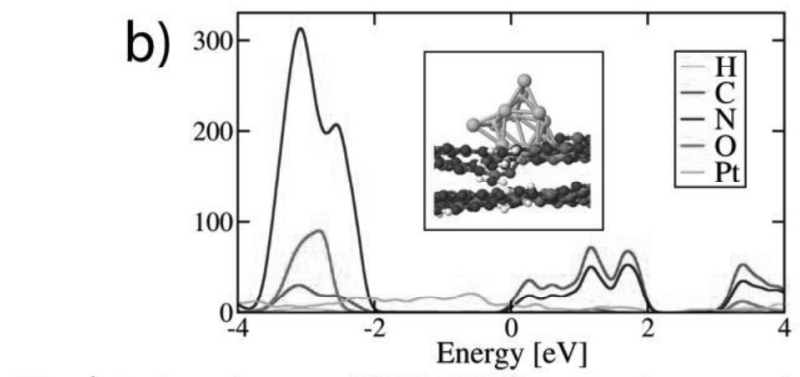

substrate

Pt cluster
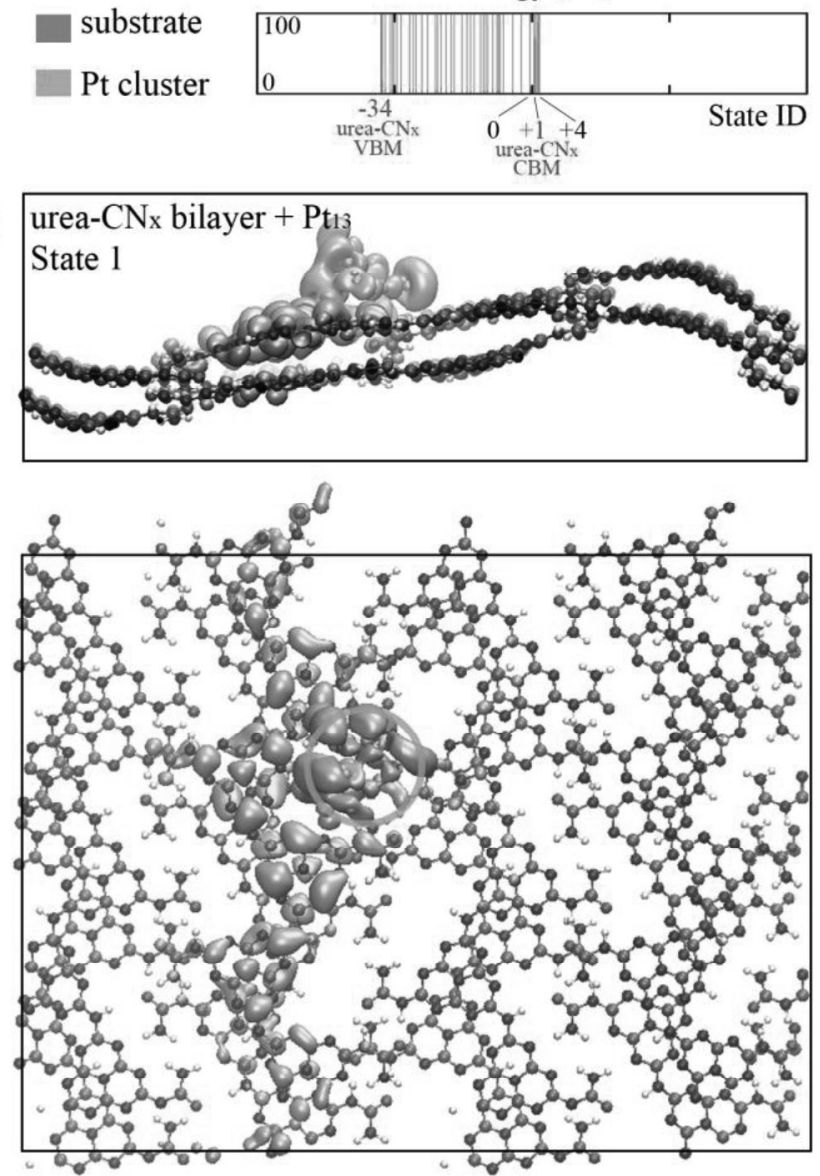

Figure 7. First-principles model of the interaction of melon versus urea- $\mathrm{CN}_{\mathrm{x}}$ with a $\mathrm{Pt}_{13}$ cluster. H: white; C: grey; N: blue; O: red; Pt: silver. a) Element-resolved smoothed partial density of states of the melon bilayer $+\mathrm{Pt}_{13}$ cluster model. Inset: $\mathrm{Pt}_{13}$ attachment via $\mathrm{NH}_{2}$ side group. b) Element-resolved smoothed partial density of states of the urea-CN $\mathrm{CN}_{\mathrm{x}}$ bilayer $+\mathrm{Pt}_{13}$ cluster model used in this work. Inset: $\mathrm{Pt}_{13}$ attachment via $\mathrm{O}$. The lower panels in a) and b) show Mulliken decompositions of selected individual levels inside the melon / urea- $\mathrm{CN}_{\mathrm{x}}$ model HOMO-LUMO gaps. Two-colored bars, grey and orange, mark the bilayer substrate vs. $\mathrm{Pt}_{13}$ cluster fractions of each state. Numbers on the $\mathrm{x}$ axes index the selected states in order of their single-particle energy, with zero indicating the highest state with a fractional occupation of 0.5 or above. c) Side and top views of the orbital density of the partially hybridized state (state ID 5 in lower panel of a) located at $0.20 \mathrm{eV}$ below the LUMO of the melon substrate (state ID 6 in lower panel of a). d) Top and side views of the orbital density of the strongly hybridized state (state ID 1 in lower panel of b) with contributions from $\mathrm{Pt}_{13}$ and from the urea-CN $\mathrm{CN}_{\mathrm{x}}$ substrate LUMO. Orange rings in the top views indicate the location of the $\mathrm{Pt}_{13}$ cluster. 
a)
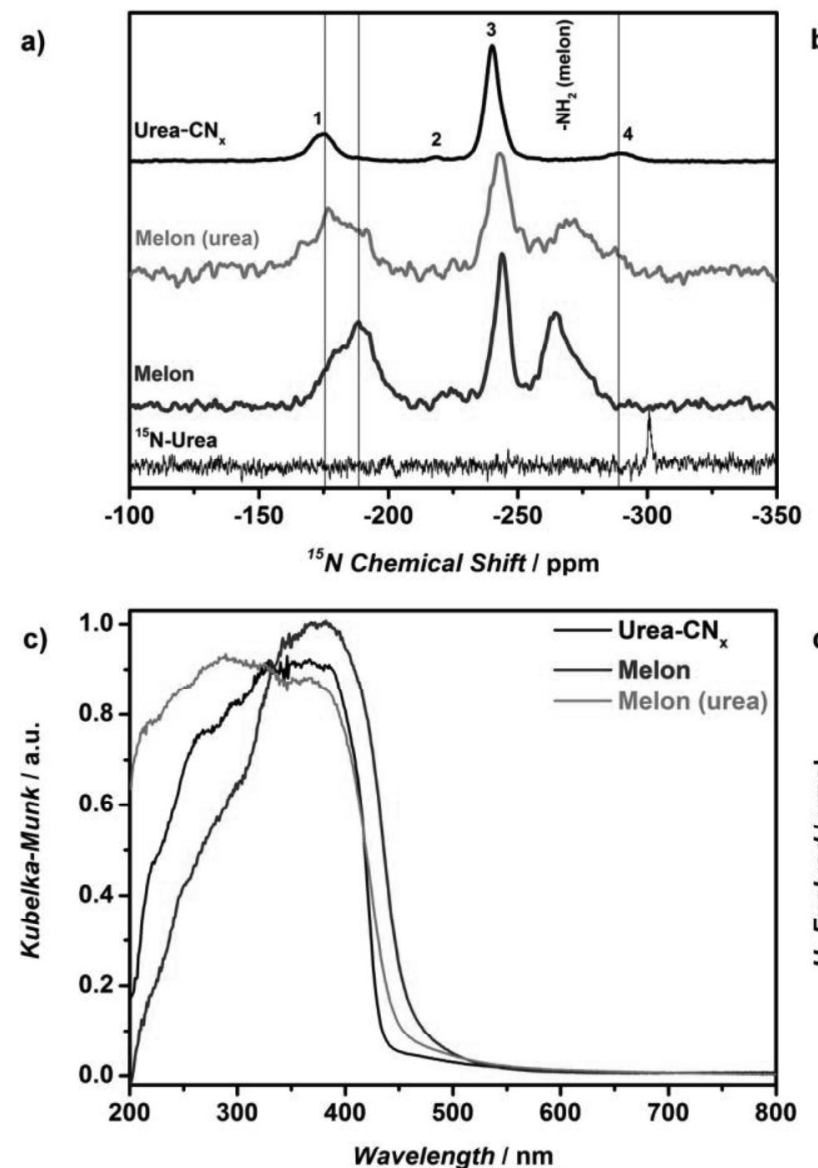

b)
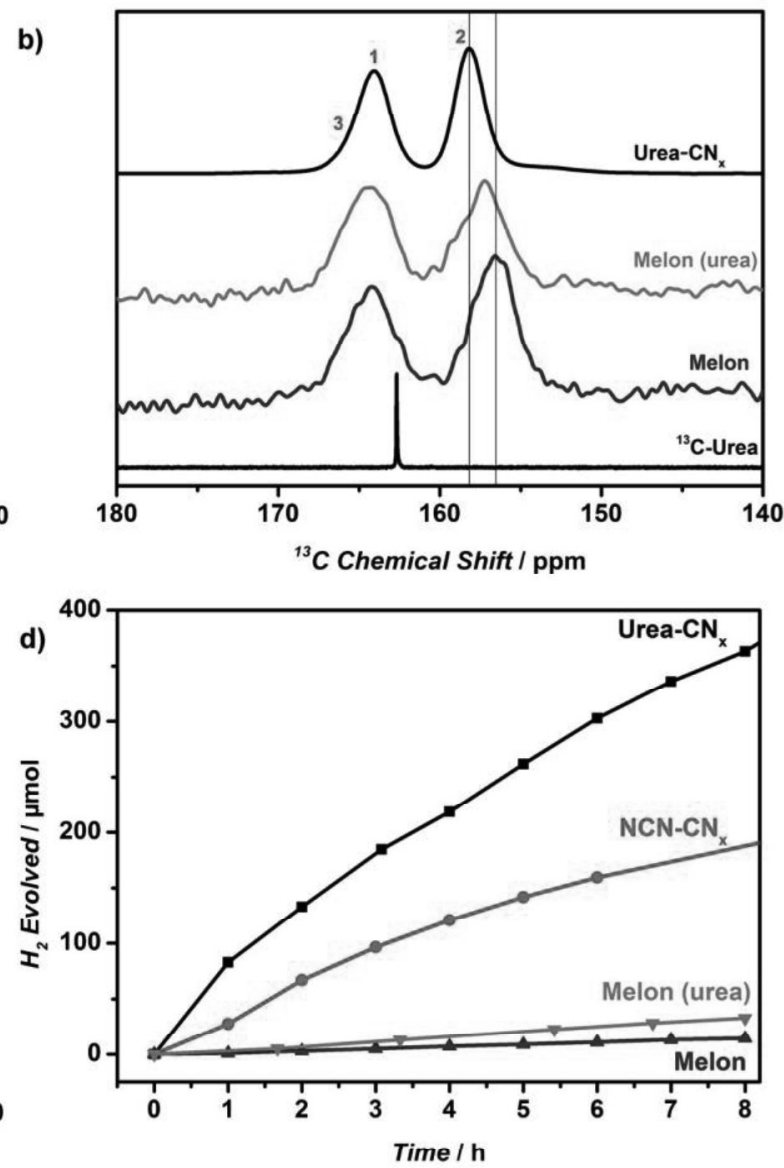

Figure 8. Comparison of urea- $\mathrm{CN}_{\mathrm{x}}$ and melon prepared from urea and melamine: a) ${ }^{15} \mathrm{~N} \mathrm{CP}$ and $\mathrm{b}$ ) and ${ }^{13} \mathrm{C}$ direct excitation NMR, with lines drawn to illustrate how the spectra for melon (urea) resemble urea- $\mathrm{CN}_{\mathrm{x}}$ as compared to melon. Identical to Figure $2 \mathrm{c}$ and $\mathrm{d}$, the black and red numbers are assignment of the ${ }^{15} \mathrm{~N}$ and ${ }^{13} \mathrm{C}$ signals, respectively, to the proposed local structure of urea- $\mathrm{CN}_{\mathrm{x}}$ (Figure $2 \mathrm{~d}$ inset). Note that both melon and melon (urea) are not isotope-enriched. c) diffuse reflectance UV-Vis spectra, and d) photocatalytic hydrogen evolution from methanol solution and AM1.5 irradiation (right).

Table 1. Elemental analyses and $\mathrm{C}: \mathrm{N}$ molar ratios of the urea-CN $\mathrm{C}, \mathrm{NCN}-\mathrm{CN}_{\mathrm{x}}$, melon, and PHI; all values are weight percentages and uncertainties are the standard deviations of measurement replicates.

\begin{tabular}{lcccccc}
\hline & $\mathrm{C}$ & $\mathrm{N}$ & $\mathrm{K}$ & $\mathrm{S}$ & $\begin{array}{c}\text { C:N molar } \\
\text { ratio }\end{array}$ & $\begin{array}{c}\text { C:N molar } \\
\text { ratio (th.) }\end{array}$ \\
\hline Urea-CN $_{\mathrm{x}}$ & $28.8 \pm 0.3$ & $48.2 \pm 0.2$ & $0.134 \pm 0.001$ & $0.017 \pm 0.004$ & $0.699 \pm 0.007$ & 0.700 \\
NCN-CN $_{\mathrm{x}}$ & $26.7 \pm 0.0$ & $44.4 \pm 0.1$ & $7.54 \pm 0.08$ & $0.17 \pm 0.11$ & $0.701 \pm 0.002$ & 0.700 \\
Melon & $35.4 \pm 0.1$ & $60.6 \pm 0.5$ & a) & a) & $0.681 \pm 0.006$ & $0.667^{\mathrm{b})}$ \\
PHI $^{\mathrm{c}}$ & 37.4 & 61.8 & - & - & - & 0.706 \\
\hline
\end{tabular}

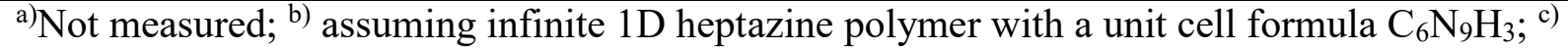
Theoretical values based on a unit cell formula of $\mathrm{C}_{12} \mathrm{~N}_{17} \mathrm{H}_{3}$ based on ref 12 , but without the central melamine 
Defective design: Graphitic carbon nitride was modified with the urea moiety as a photocatalytically relevant "defect", yielding a material with a sacrificial photocatalytic hydrogen evolution rate well over an order of magnitude higher than that of the unmodified counterpart. The outperformance is attributed to metal-support interaction between the urea group and the Pt co-catalyst, thereby facilitating interfacial electron transfer.

\section{Keyword: Photocatalysis}

Vincent Wing-hei Lau, Victor Wen-zhe Yu, Florian Ehrat, Tiago Botari, Igor Moudrakovski, Thomas Simon, Viola Duppel, Elise Medina, Jacek Stolarczyk, Jochen Feldmann, Volker Blum, and Bettina V. Lotsch*

Urea-modified carbon nitrides: Enhancing Photocatalytic Hydrogen Evolution by Rational Defect Engineering

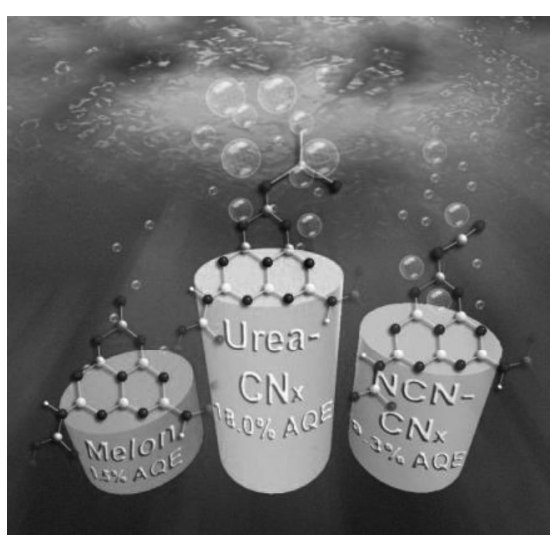




\section{Supporting Information}

\section{Urea-modified carbon nitrides: Enhancing Photocatalytic Hydrogen Evolution by Rational Defect Engineering}

Vincent Wing-hei Lau, Victor Wen-zhe Yu, Florian Ehrat, Tiago Botari, Igor Moudrakovski, Thomas Simon, Viola Duppel, Elise Medina, Jacek Stolarczyk, Jochen Feldmann, Volker Blum, and Bettina V. Lotsch 


\section{Experimental details}

All chemicals used are reagent grade purity. Melon and $\mathrm{NCN}-\mathrm{CN}_{\mathrm{x}}$ were prepared following published procedures. Briefly, melon was prepared by heating melamine (14 g) unless otherwise stated, loaded in a lidded quartz boat, in a tube furnace under argon at $550{ }^{\circ} \mathrm{C}$ at $5{ }^{\circ} \mathrm{C} \mathrm{min}^{-1}$ for $12 \mathrm{~h}$. After cooling to ambient temperature, the yellow solid obtained was thoroughly ground in a ceramic mortar and pestle prior to further processing and analysis (yield 6-7 g). NCN-CN $\mathrm{N}_{\mathrm{x}}$ was prepared in a salt melt of $\mathrm{KSCN}$ as follows. Melon (1.5 g) was thoroughly mixed in a ceramic mortar and pestle with $\mathrm{KSCN}$ (3.0 g, dried overnight at $140{ }^{\circ} \mathrm{C}$ in vacuum) and the resulting mixture was loaded in an alumina boat. The mixture was then heated in a tube furnace under argon to $400{ }^{\circ} \mathrm{C}$ for $1 \mathrm{~h}$, then at $500{ }^{\circ} \mathrm{C}$ for $30 \mathrm{~min}$, both at maximum ramp. After cooling to ambient temperature, the product was washed repeatedly with water until all residue of KSCN was removed as judged by XRD, then dried at $60{ }^{\circ} \mathrm{C}$ in a vacuum oven, yielding $1.3 \mathrm{~g}$ of the product as a yellow solid. Urea- $\mathrm{CN}_{\mathrm{x}}$ was prepared by adding aqueous $\mathrm{HCl}(50 \mathrm{~mL}, 1 \mathrm{M})$ to $\mathrm{NCN}_{-} \mathrm{CN}_{\mathrm{x}}(600 \mathrm{mg})$, whereupon the yellow solid immediately turned off-white. After several hours of stirring, the solid was isolated by centrifugation, washed repeatedly with water, then dried at $60{ }^{\circ} \mathrm{C}$ in vacuum. Batch to batch variation of photocatalytic activity is shown in Figure S1.

Melon (urea) was prepared by heating urea (19.4 g) in a lidded quartz boat in a tube furnace under argon flow at $550{ }^{\circ} \mathrm{C}$ at $5{ }^{\circ} \mathrm{C} \mathrm{h}^{-1}$ ramp for $12 \mathrm{~h}$. The color of the product is pale yellow with yield of 4-5 g.

\section{Instrumental details}

X-ray diffraction patterns were collected using a STOE Stadi P diffractometer $(\mathrm{Cu} \mathrm{K \alpha 1)}$ in Debye-Scherrer configuration. ATR-IR spectra were collected with a PerkinElmer UATR TWO spectrometer equipped with a diamond crystal. Diffuse reflectance UV-Vis spectra were collected on a Cary 5000 spectrometer (referenced to PTFE or barium sulfate) and the 
spectra in percentage reflectance were converted using the Kubelka Munk function. From these spectra, the optical gaps were extracted assuming direct transition.

CHN elemental analyses were performed with a Vario El element analyzer (Elementar Analysensysteme $\mathrm{GmbH}$ ). Other elements were quantified with a Vista Pro Simultaneous ICP-OES Spectrometer combined with axially plasma system as excitation source and echelle polychromator with CCD detector (Varian Darmstadt). Calibrations were carried out by standard addition and the data were analyzed by the ICP-Expert software. Samples were digested in concentrated $\mathrm{HNO}_{3}$ at $150{ }^{\circ} \mathrm{C}$ for $14 \mathrm{~h}$ in a Teflon-lined autoclave.

Liquid state ${ }^{1} \mathrm{H},{ }^{13} \mathrm{C}$ and ${ }^{15} \mathrm{~N}$ NMR spectra were collected on a Bruker Avance $300 \mathrm{MHz}$ NMR spectrometer at resonance frequencies of $300,75.5$ and $30.4 \mathrm{MHz}$, respectively $\left(\mathrm{B}_{0}=\right.$ 7.04 T). Solid-state ${ }^{1} \mathrm{H},{ }^{13} \mathrm{C}$ and ${ }^{15} \mathrm{~N}$ NMR experiments were performed on a Bruker AvanceIII $400 \mathrm{MHz}$ instrument at the frequencies of $400,100.61$ and $40.53 \mathrm{MHz}$, respectively ( $\mathrm{B}_{0}=$ 9.4 T). Chemical shifts for ${ }^{1} \mathrm{H}$ and ${ }^{13} \mathrm{C}$ are referenced to tetramethylsilane (TMS, $\delta\left({ }^{1} \mathrm{H},{ }^{13} \mathrm{C}\right)=$ $0.0 \mathrm{ppm}$ ), while ${ }^{15} \mathrm{~N}$ is referenced to nitromethane ( $\delta=0.0 \mathrm{ppm}$, with positive shifts to higher frequency). Magic Angle Spinning (MAS) with spinning rates ranging between 10 and 12.5 $\mathrm{kHz}$ was used in all experiments on solids. ${ }^{13} \mathrm{C}$ spectra with cross-polarization (CP) were recorded with a ramped polarization mixing and SPINAL-64 proton decoupling $\left({ }^{1} \mathrm{H}\right.$ RF field of $80 \mathrm{kHz}){ }^{[1]}$ Quantitative ${ }^{13} \mathrm{C}$ spectra were acquired in a direct excitation mode with relaxation delay between the consecutive scans set to $900 \mathrm{~s}$. This relaxation delay was at least 4 times the longest $T_{1}$ in all carbon sites in the materials studied, as estimated from preliminary relaxation time measurements. Between 160 and 256 scans were commonly accumulated, with all experiments accompanied by SPINAL-64 decoupling. ${ }^{1} \mathrm{H}-{ }^{13} \mathrm{C}$ and ${ }^{1} \mathrm{H}-$ ${ }^{15} \mathrm{~N}$ frequency switched Lee-Goldburg hetero-nuclear correlations (FSLG HETCOR) experiments ${ }^{[2]}$ were carried out with ramped cross polarization, ${ }^{1} \mathrm{H} R \mathrm{RF}=100 \mathrm{kHz}$, and spinning speed of $12.5 \mathrm{kHz}$. Short mixing times of $50-150 \mu$ s were used in order to avoid 
long range polarization transfer. A total of 128 increments were made in an indirect dimension $\left({ }^{1} \mathrm{H}\right)$, with 560 acquisitions per increment. Deconvolution and integration of the solid state spectra were carried out using the Dmfit software version 20111221. ${ }^{[3]}$ A CrossPolarization with Polarization Inversion (CPPI) experiment implemented previously reported pulse sequences. ${ }^{[4]}$ A ramped mixing pulse of $5 \mathrm{~ms}$ was followed by a proton polarization inverting pulse in a range of 10 to $500 \mu \mathrm{s}$. In Double Cross-Polarizations (DCP) experiments $^{[5]}$ the first CP step transfers magnetization from protons to ${ }^{15} \mathrm{~N}$. Then, in a second cross polarization step, magnetization is transferred from ${ }^{15} \mathrm{~N}$ to ${ }^{13} \mathrm{C}$. The signal is detected on ${ }^{13} \mathrm{C}$ under SPINAL-64 proton decoupling. Ramped and tangential mixing pulses were used in the consecutive cross-polarization steps with optimized durations of $0.4-0.6 \mathrm{~ms}$ and $9 \mathrm{~ms}$. A total of 128 increments were made in an indirect dimension $\left({ }^{15} \mathrm{~N}\right)$, with 192 acquisitions per increment and a relaxation delay of $2 \mathrm{~s}$.

Sorption measurements were performed on a Quantachrome Autosorb iQ gas sorption analyzer using argon as the sorbent at $87.45 \mathrm{~K}$. Samples were outgassed for overnight at $150{ }^{\circ} \mathrm{C}$ to a vacuum of $10^{-7}$ mbar. Surface areas were calculated using Brunauer-EmmettTeller (BET) theory from the argon adsorption isotherms of the samples. Pore size distribution and volume were calculated from the adsorption isotherm employing either the non-local (NLDFT) or quenched solid density functional theory (QSDFT) using the "ArCarbon cylindrical pores at $87 \mathrm{~K}$ " or the "Ar-Carbon slit pores at $87 \mathrm{~K}$ " kernel (applicable pore diameters $0.35-36 \mathrm{~nm}$ ) as implemented in the AUTOSORB data reduction software. Transmission electron microscopy (TEM) was performed with a Philips CM30 ST (300 kV, LaB6 cathode). The samples were suspended in n-butanol and drop-cast onto a lacey carbon film (Plano). Scanning electron microscopy (SEM) was performed on a Zeiss Merlin electron microscope. 
For X-ray photoelectron spectroscopy (XPS), samples were pressed onto indium foil and the spectra were collected on an Axis Ultra (Kratos Analytical, Manchester) X-ray photoelectron spectrometer with charge neutralization. The spectra were processed using the software CasaXPS 2.3.16. The spectra were referenced with the adventitious carbon $1 \mathrm{~s}$ peak at $284.80 \mathrm{eV}$. Binding energies were compared with the NIST Standard Reference Database 20 (Version 4.1) unless otherwise specified.

Thermogravimetric analysis coupled with mass spectroscopy (TGA-MS) was performed with the instrument STA 409 C (Netzsch GmbH, Selb, Germany) connected with a quadrupole mass spectrometer QMS 422 (Balzers, Hudson, USA). Samples were loaded in alumina crucibles and heated under argon $\left(100 \mathrm{~mL} \mathrm{~min}^{-1}\right)$ from ambient temperature to $900{ }^{\circ} \mathrm{C}$ at a ramp rate of $1^{\circ} \mathrm{C} \mathrm{min}^{-1}$.

Static photoluminescence (PL) spectra were acquired with a Horiba Jobin Yvon Fluorolog-3 FL3-22 spectrometer equipped with a water-cooled Horiba R928 PMT detector. Fluorescence was detected at an angle of $160^{\circ}$ with respect to the excitation source. The samples were measured at a suspension concentration of $1 \mathrm{mg} \mathrm{mL}^{-1}$ in water or aqueous methanol solution (10 vol\%). The suspension was stirred during the measurement to prevent suspension sedimentation.

Time resolved fluorescence measurements were carried out with a TCSPC setup. A NKT SuperK white light laser with ExtendUV was used as the excitation source at $375 \mathrm{~nm}$. The fluorescence was recorded by an avalanche photodiode mounted to a spectrometer and a PicoQuant TimeHarp 260. The same sample suspensions as for the static PL measurements were used and also stirred during the measurements.

Zeta potentials were measured on a Malvern Zetasizer Nano ZS. The carbon nitride sample was suspended at concentration of $0.1 \mathrm{mg} \mathrm{mL}^{-1}$ in solutions of various $\mathrm{pH}$ adjusted by $\mathrm{HCl}$ or 
$\mathrm{NaOH}$, with the ionic strength maintained at $10 \mathrm{mM}$ using $\mathrm{NaCl}$. The suspension was sonicated for $15 \mathrm{~min}$ before loading in a folded capillary cell (Malvern) for measurement.

\section{Photocatalytic experiments}

Photocatalytic experiments were performed in a double-walled glass reactor, where the outer compartment is circulated with thermostated water $\left(25^{\circ} \mathrm{C}\right)$, as previously described. ${ }^{[6]}$ In the platinum-free cases, the reactor and magnetic stirrer were cleaned with aqua regia prior to the photocatalysis experiment. The reactor was top-irradiated through a quartz window with a xenon lamp (Newport, $300 \mathrm{~W}$ ) equipped with a water filter and a full spectrum mirror $(2000 \mathrm{~nm}>\lambda>200 \mathrm{~nm})$. An air mass (AM) 1.5 filter was also used where specified. Unless stated otherwise, for a standard photocatalytic experiment, the catalyst powder $(20 \mathrm{mg})$ was suspended in a solution of water $(18 \mathrm{~mL})$, methanol $(2 \mathrm{~mL})$ and dihydrogen hexachloroplatinate $(5 \mu \mathrm{L}, 8 \mathrm{wt} \%$ aqueous solution, Aldrich), which forms the platinum cocatalyst from its $i n$-situ reduction. This platinum amount yields a loading of around $1 \mathrm{wt} \%$. The photocatalytic experiments in pure water followed an identical procedure, except that only water $(20 \mathrm{~mL})$ was used (i.e. no methanol nor dihydrogen hexachloroplatinate). The headspace was subjected to several cycles of evacuation and argon backfill prior to the experiment. In the course of the experiment, the headspace of the reactor was periodically sampled and hydrogen was quantified by gas chromatography (Thermo Scientific TRACE GC Ultra) equipped with a TCD detector using argon as the carrier gas.

After the photocatalytic experiment, the catalyst was recovered by centrifugation, washed with water, then dried at $60{ }^{\circ} \mathrm{C}$ in vacuum. For quick optimization of platinum loading, the photocatalytic experiments were performed in disposable septum-capped glass vials containing the catalyst $(10 \mathrm{mg})$, water $(9 \mathrm{~mL})$ and methanol $(1 \mathrm{~mL})$ and a variable amount of dihydrogen hexachloroplatinate solution. The vial was stirred whilst irradiated using a xenon lamp as above for $3 \mathrm{~h}$, then the hydrogen in the headspace was quantified. Experiments for 
the estimation of quantum efficiency were conducted using band pass filters with band centers at $400 \mathrm{~nm}$ and $500 \mathrm{~nm}$ with full width half maximum of $50 \mathrm{~nm}$ (Thorlab). Irradiance of the incident light was measured using a thermopile (Thorlabs) and photon flux was estimated using the integral of the transmission spectra of the band pass filters. Apparent quantum efficiency (AQE) was then calculated as:

$$
A Q E[\%]=\frac{2 \times \text { Hydrogen Evolution Rate }\left[\mathrm{mol} \mathrm{h}^{-1}\right]}{\text { Photon Flux }\left[\mathrm{mol} \mathrm{h}^{-1}\right]}
$$

Further details of our photocatalytic experiments (e.g. schematic of our set-up, reactor configuration, spectra of our irradiation sources) can be found in our previous publication. ${ }^{[6]}$ 


\section{Alternative structures of $\mathrm{NCN}-\mathrm{CN}_{\mathrm{x}}$ and urea-CN $\mathrm{CN}_{\mathrm{x}}$}

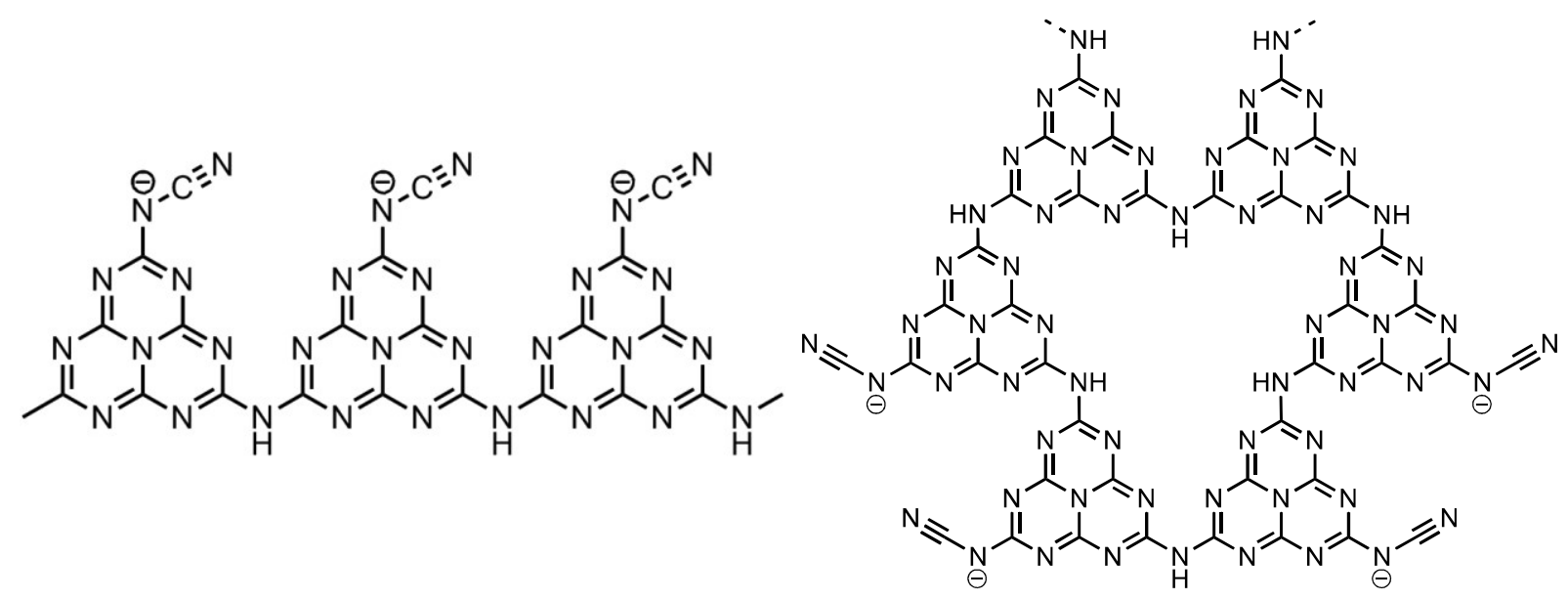

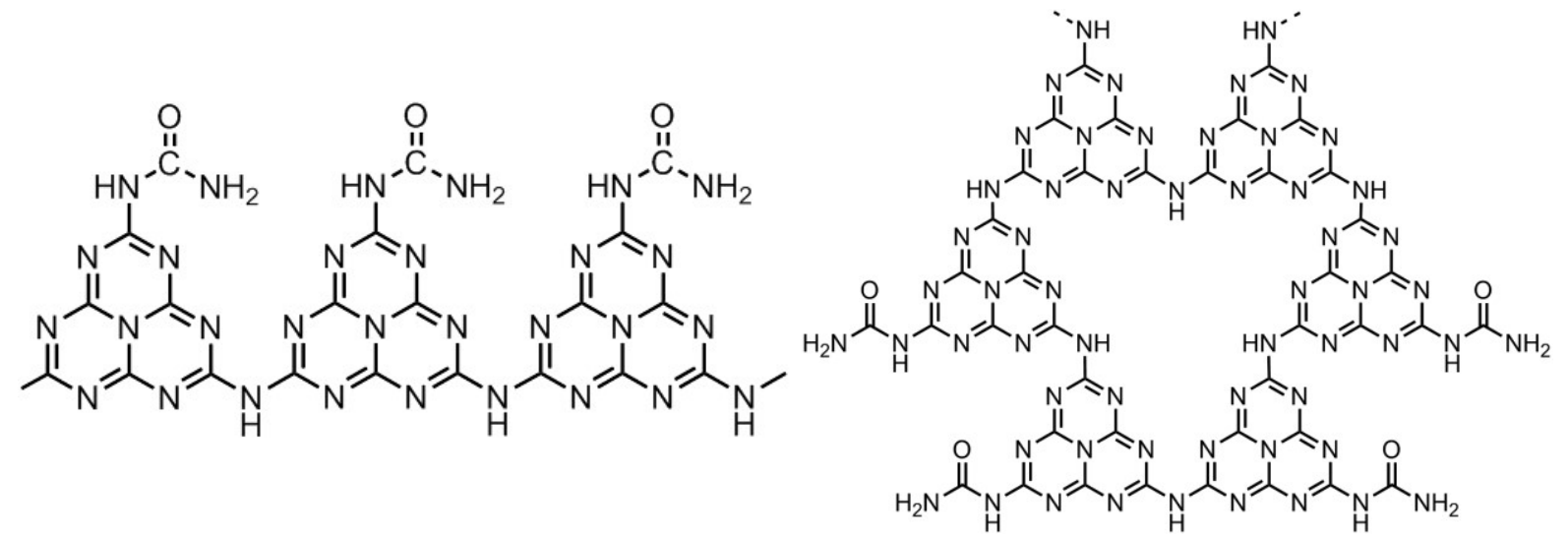

Scheme S1 Structures of $\mathrm{NCN}-\mathrm{CN}_{\mathrm{x}}$ (top row) and urea-CN $\mathrm{N}_{\mathrm{x}}$ (bottom row) based on the 1D polymeric structure (left column) and the PHI network structure (right column). 


\section{Characterization of urea-CN $\mathrm{N}_{\mathrm{x}}$ and other carbon nitrides}
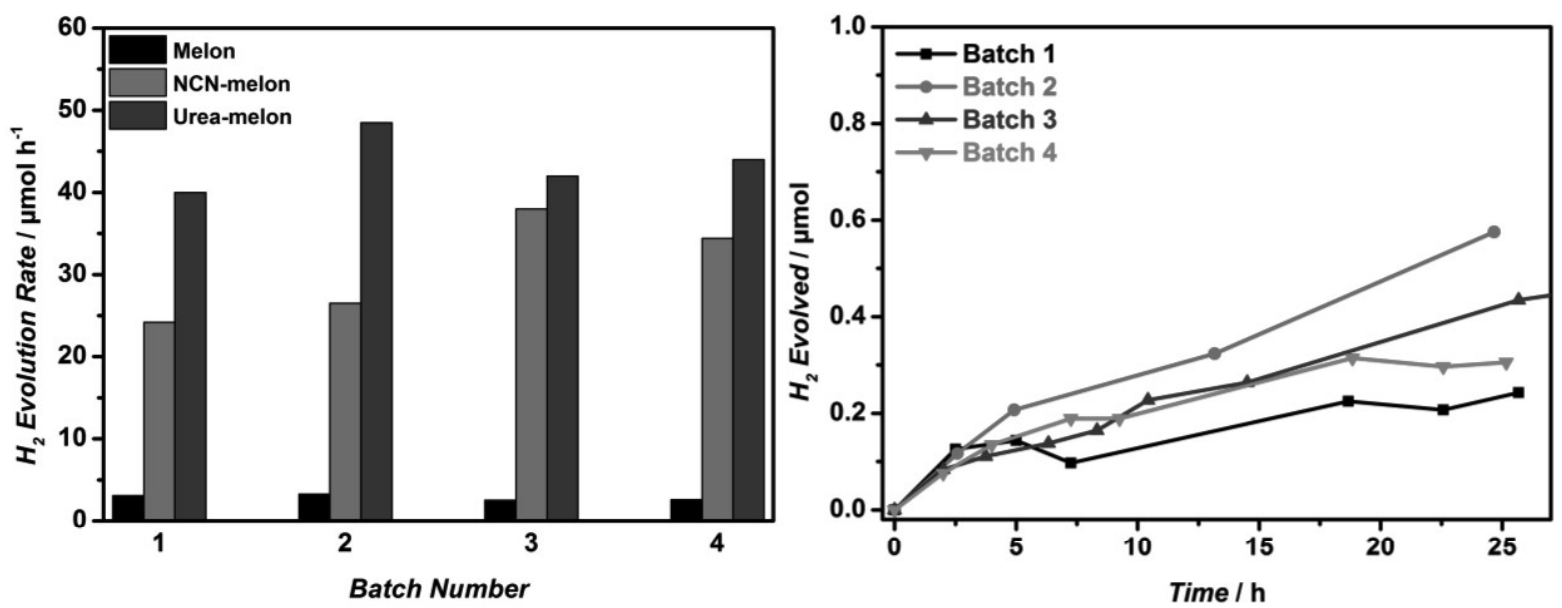

Figure S1 Variation of photocatalytic activity of four batches of catalysts under AM1.5 irradiation and methanol (10 vol\%) as electron donor. Left: initial photocatalytic hydrogen evolution (average rate of first six hours) for the carbon nitrides at optimized platinum loading. Right: platinum-free hydrogen evolution of urea- $\mathrm{CN}_{\mathrm{x}}$ for the first $25 \mathrm{~h}$.

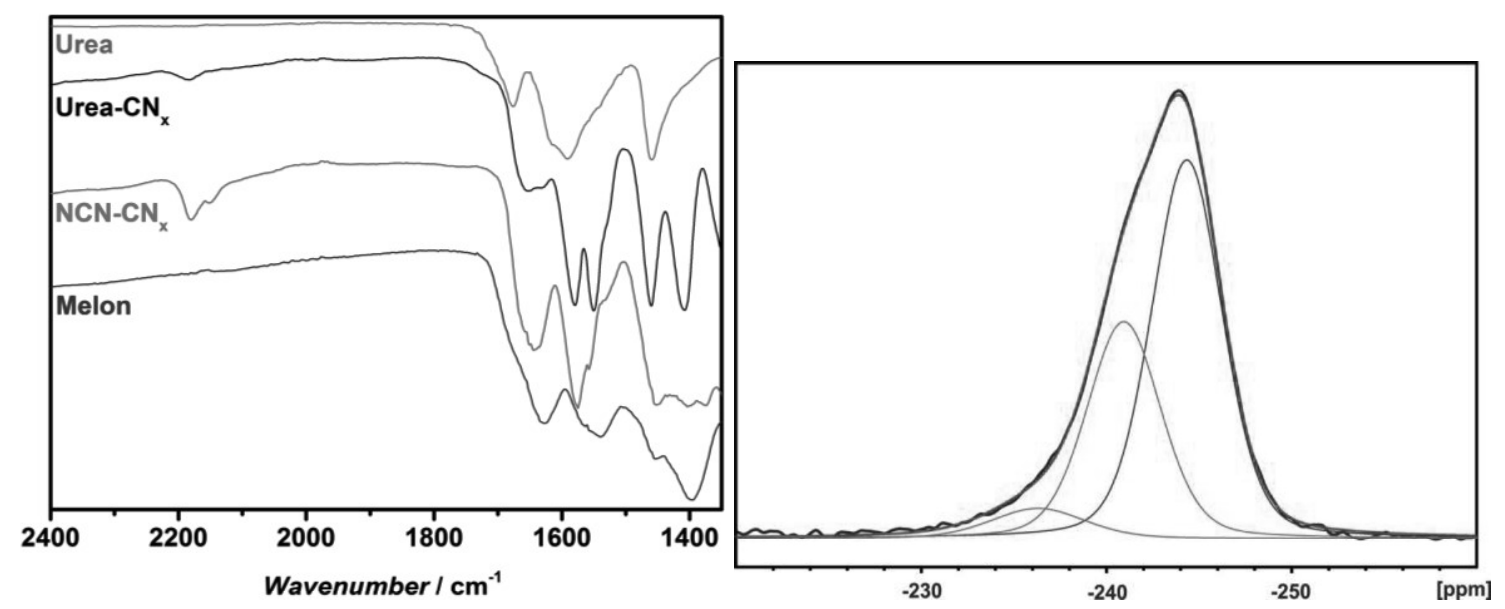

Figure S2 Left: enlarged version of the FTIR spectra in Figure 2a, focusing on the cyanamide $\left(2300-2100 \mathrm{~cm}^{-1}\right)$ and urea region $\left(1800-1400 \mathrm{~cm}^{-1}\right)$. Right: deconvolution of the $\mathrm{N} 3$ signal from the ${ }^{15} \mathrm{~N}$ CP spectrum of urea- $\mathrm{CN}_{\mathrm{x}}$. 

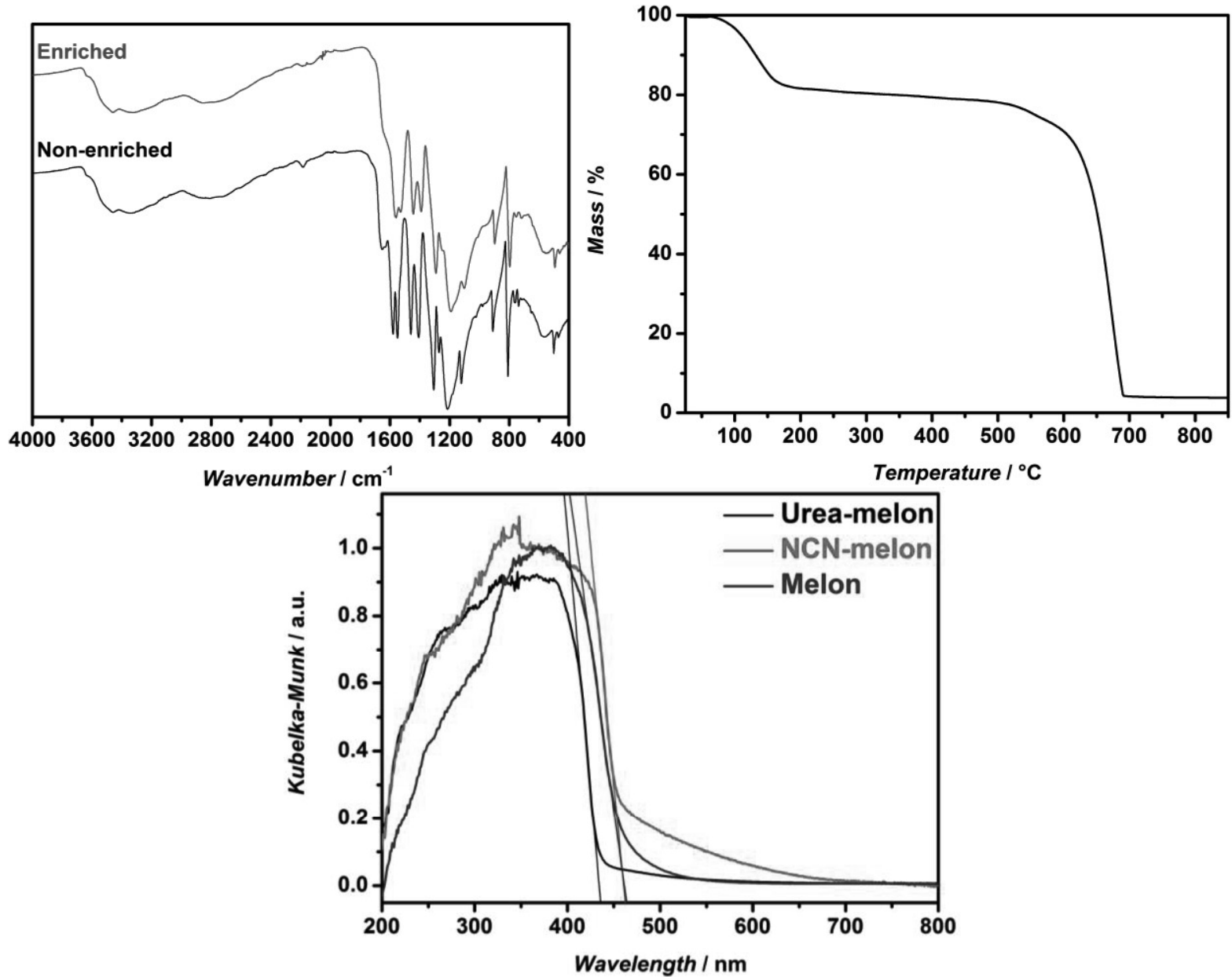

Figure S3 Top left: comparison of the FTIR spectra of urea- $\mathrm{CN}_{\mathrm{x}}$ of natural isotope abundance and the sample prepared from ${ }^{13} \mathrm{C}$ and ${ }^{15} \mathrm{~N}$ enriched $\mathrm{KSCN}$; top right: thermogravimetric analysis of urea-CN $\mathrm{N}_{\mathrm{x}}$; bottom: diffuse reflectance spectra and extraction of their optical gaps.
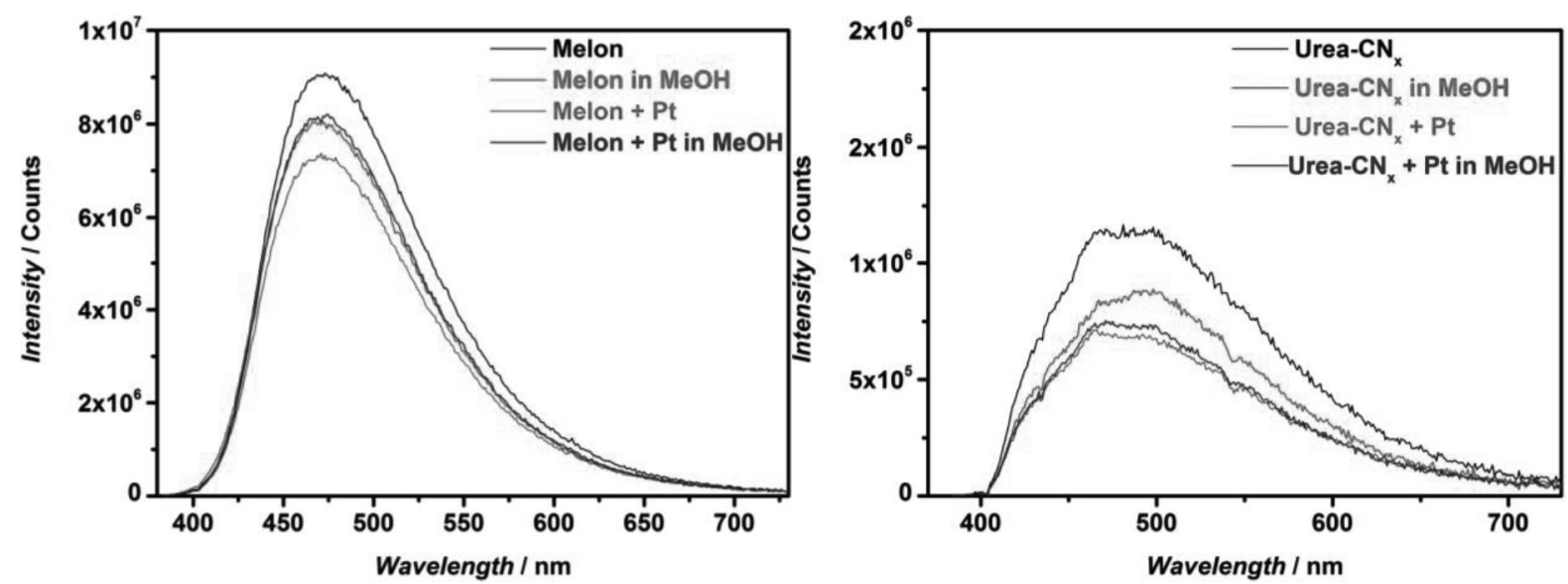

Figure S4 Steady state PL spectra of melon (left) and urea-CN $\mathrm{N}_{\mathrm{x}}$ (right). 
Table S1 Elemental analyses of urea- $\mathrm{CN}_{\mathrm{x}}$ before and after $100+\mathrm{h}$ photocatalysis. All values unless otherwise stated are weight percentages and uncertainties are the standard deviations of the measurement replicates.

\begin{tabular}{lccccc} 
& $\mathrm{C}$ & $\mathrm{N}$ & $\mathrm{Pt}$ & $\mathrm{C}: \mathrm{N}$ molar ratio & Residual Weight (\%) \\
\hline Pristine & $28.9 \pm 0.3$ & $48.2 \pm 0.2$ & - & $0.698 \pm 0.007$ & 19.6 \\
& & & & & \\
Spent & $27.9 \pm 0.3$ & $45.0 \pm 0.1$ & $0.77 \pm 0.01$ & $0.724 \pm 0.007$ & 21.2 \\
\hline
\end{tabular}

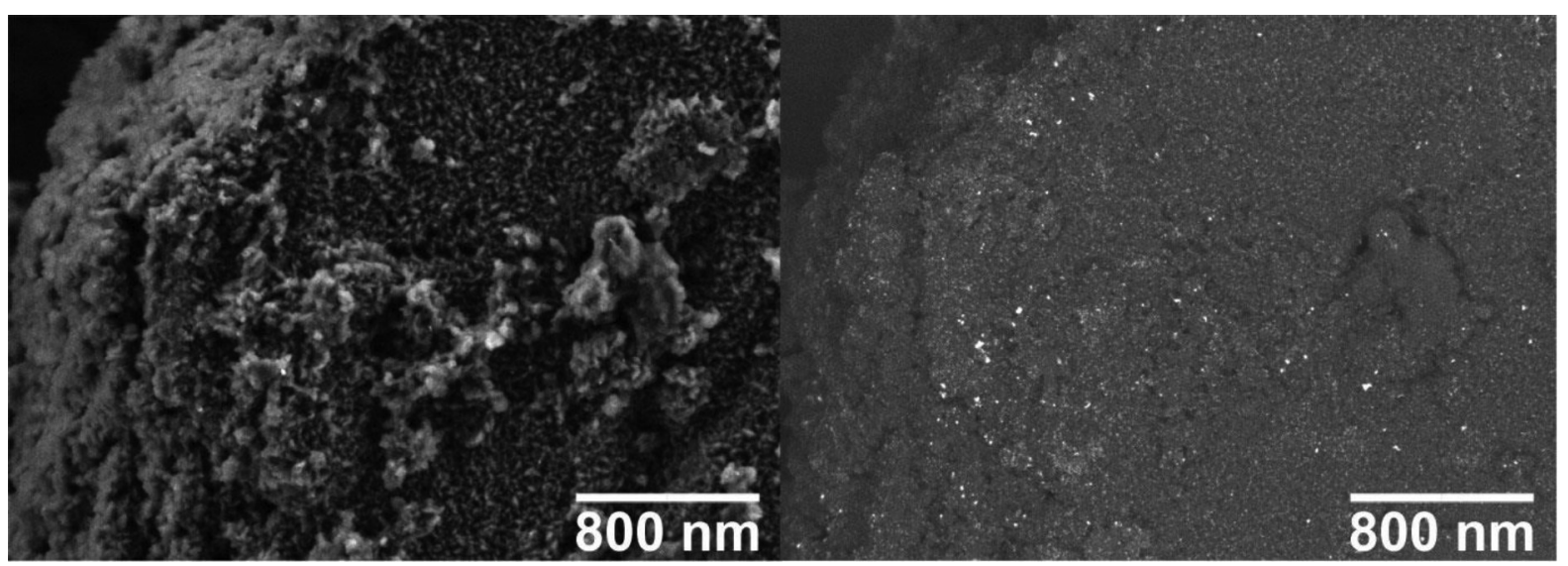

Figure S5 SEM images of the spent urea- $\mathrm{CN}_{\mathrm{x}}$ using the secondary electron detector (left) and backscattered electron detector (right), the latter of which shows the platinum particles as bright spots.

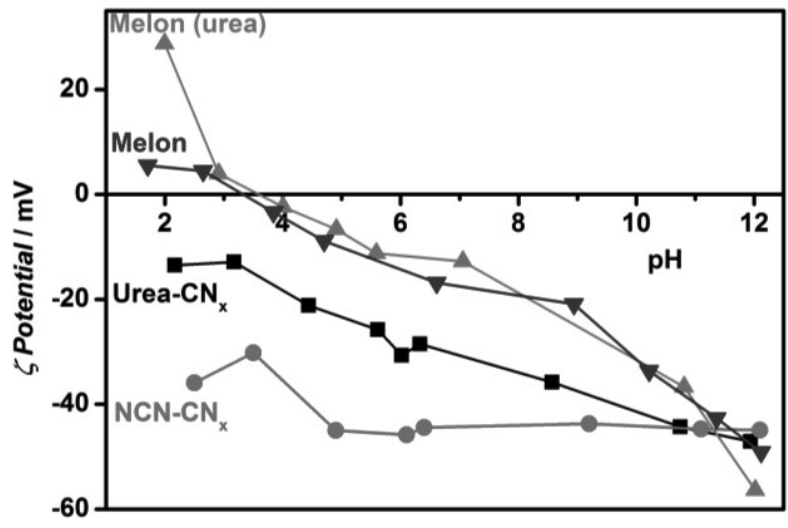

Figure S6 Zeta-potentials of the carbon nitrides studied in this work. 

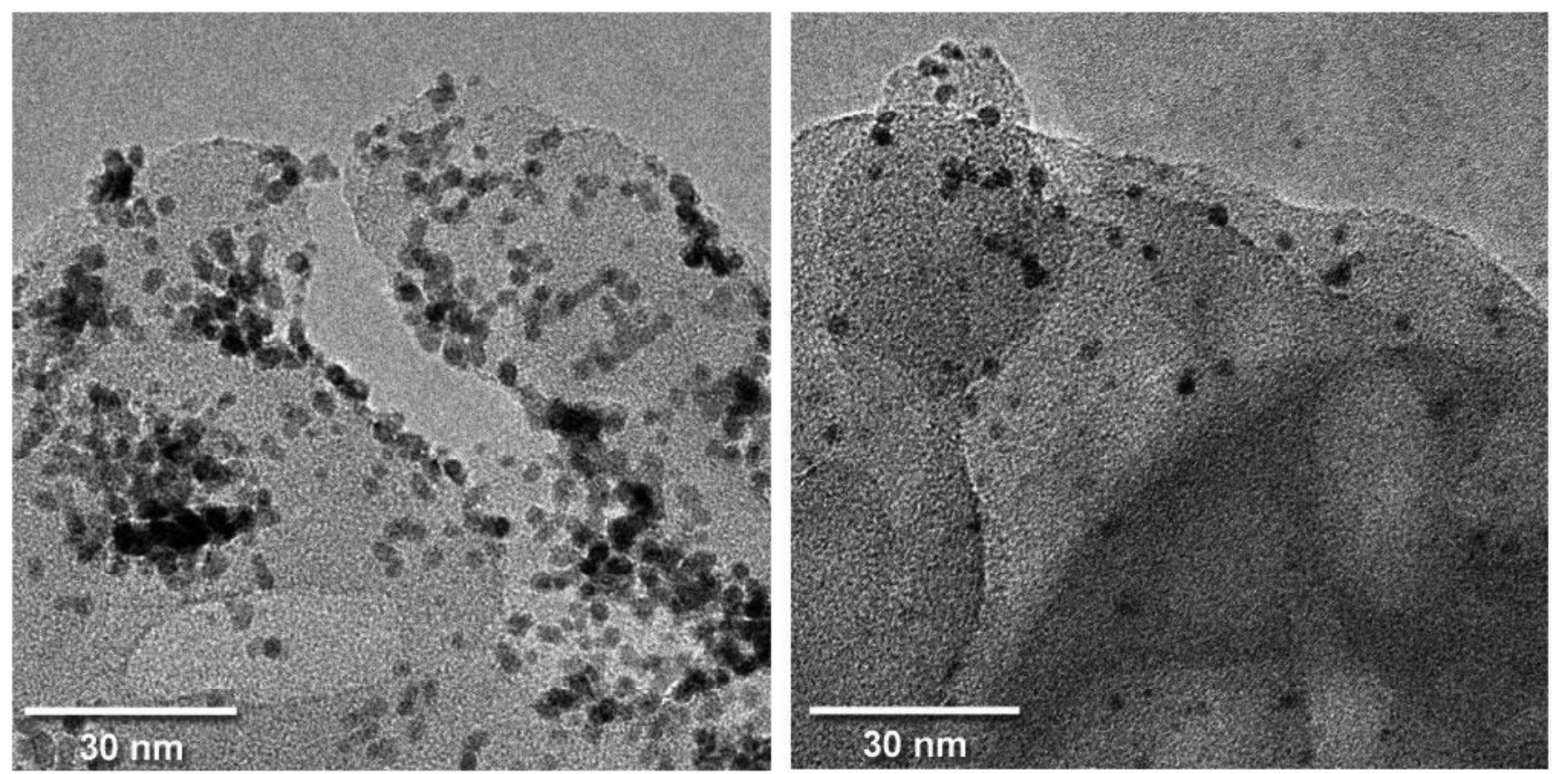

Figure S7 TEM images of melon (left) and melon (urea) (right) after photocatalytic reaction, showing the photo-deposited platinum clusters as dark spots.

By comparing the structure-property-activity relationship in these four carbon nitrides, we can identify the dominant factor leading to high photocatalytic activity in these materials. In agreement with the results from Martin et al, ${ }^{[7]}$ we can rule out BET surface area based on the differences in their intrinsic activity (hydrogen evolution rate normalized for BET surface area, column 6 in Table S3). Since the hydrogen evolution rate is for illumination under the entire AM1.5 spectrum, the low value for melon (urea) here does not take into account its much higher activity under $400 \mathrm{~nm}$ irradiation (c.f. AQE values for the four samples). We also rule out water dispersibility as measured by zeta potential (Figure S6) since, at $\mathrm{pH} \approx 5$ where the photocatalytic experiments were performed, the second most active $\mathrm{NCN}-\mathrm{CN}_{\mathrm{x}}$ has the highest dispersibility due to its anionic charge, while melon (urea) and melon have nearly identical zeta potential despite the former being twice as active as the latter. The most active material, urea-CN $\mathrm{C}_{\mathrm{x}}$, has zeta potential in-between $\mathrm{NCN}-\mathrm{CN}_{\mathrm{x}}$ and the two melon samples. Note that melon is the only sample out of the four that shows significant settling. Zeta potential here thus measures only the melon particles that are sufficiently small $(<2 \mu \mathrm{m})$ to maintain colloidal stability. 
The photo-deposited Pt co-catalyst in all four platinized samples are nearly spherical with diameter in the range of 2-4 nm (Figure S7 for platinized melon and melon (urea); see reference [8] for $\mathrm{NCN}-\mathrm{CN}_{\mathrm{x}}$ ) at loading of below $1 \mathrm{wt} \%$ for all but the $\mathrm{NCN}-\mathrm{CN}_{\mathrm{x}}$ sample (Table S2 for elemental analyses). From the similarity of the Pt size and morphology as well as the absence of correlation between optimized Pt loading and hydrogen evolution rate, we thus rule these out as factors for the activity difference. Lastly, we observed that the $\mathrm{Pt}$ particles on urea- $\mathrm{CN}_{\mathrm{x}}$ and melon (urea) are distributed over the entire carbon nitride surface, while those of melon suffer from aggregation; note that the apparent aggregation of Pt on $\mathrm{NCN}-\mathrm{CN}_{\mathrm{x}}$ is due to the much higher optimized Pt loading ( $5 \mathrm{wt} \%$ for $\mathrm{NCN}-\mathrm{CN}_{\mathrm{x}} \mathrm{vs} 0.8 \mathrm{wt} \%$ for urea- $\left.\mathrm{CN}_{\mathrm{x}}\right)$. The metal-support interaction described in the computational section can rationalize these results as this effect is known to enhance the dispersion of metal nanoparticles as they nucleate, ${ }^{[9]}$ which we believe to operate for urea- $\mathrm{CN}_{\mathrm{x}}$ as well. However, this dispersibility in itself does not explain the order-of-magnitude difference in hydrogen evolution rate between urea- $\mathrm{CN}_{\mathrm{x}}$ and melon (urea). Having eliminated these aforementioned factors, we thus deduce efficient charge transfer mediated by the platinum/urea- $\mathrm{CN}_{\mathrm{x}}$ interaction to be a key determinant for its high activity. Future work examining this interface in details may clarify the role of such metal-support interaction, and may enable further improvement in the catalyst design process. 


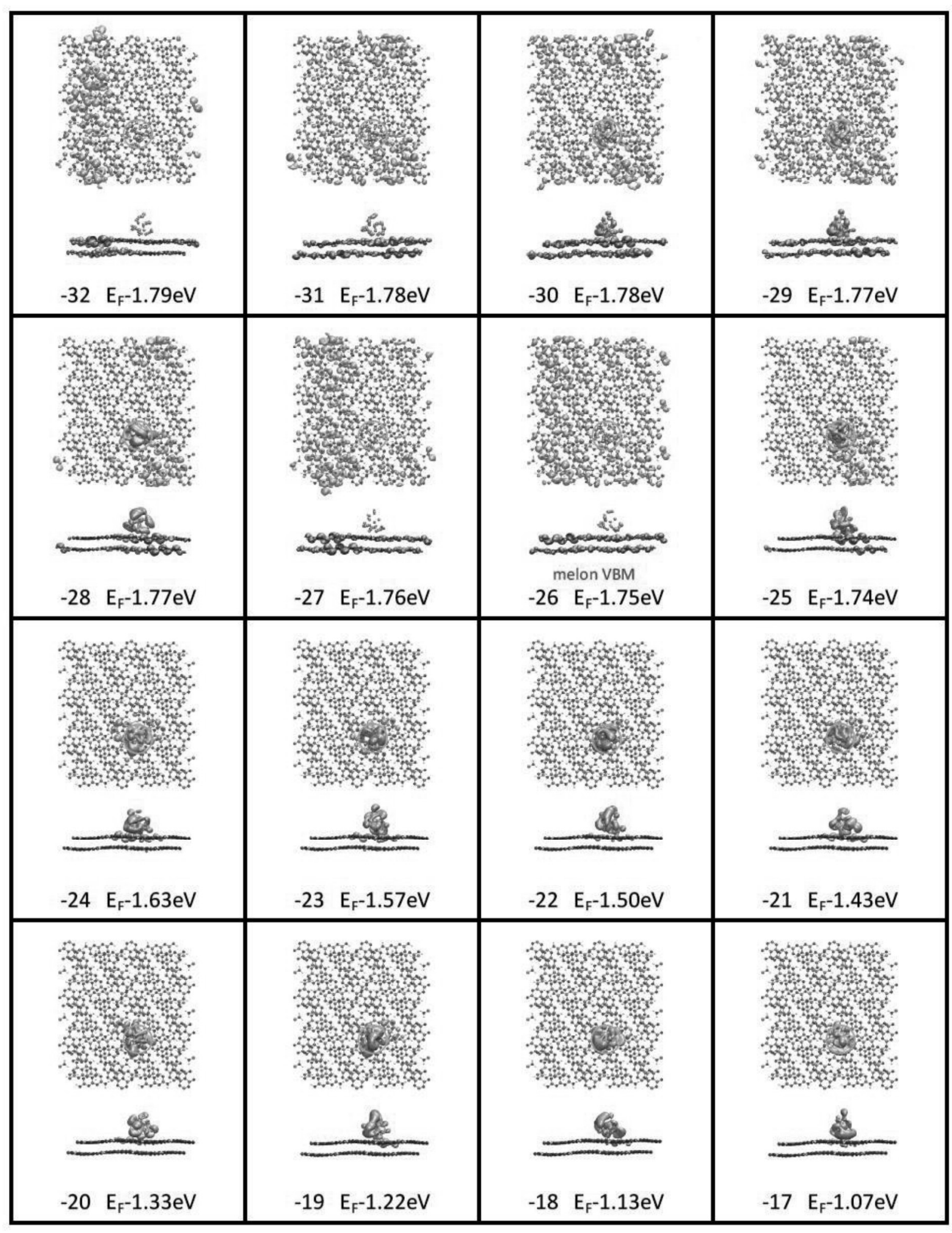

Figure S8 Part 1 of the orbital plots of $\mathrm{Pt}_{13}-\mathrm{Melon}$ from just below the valence band maximum (VBM) to just above the conduction band minimum (CBM) 


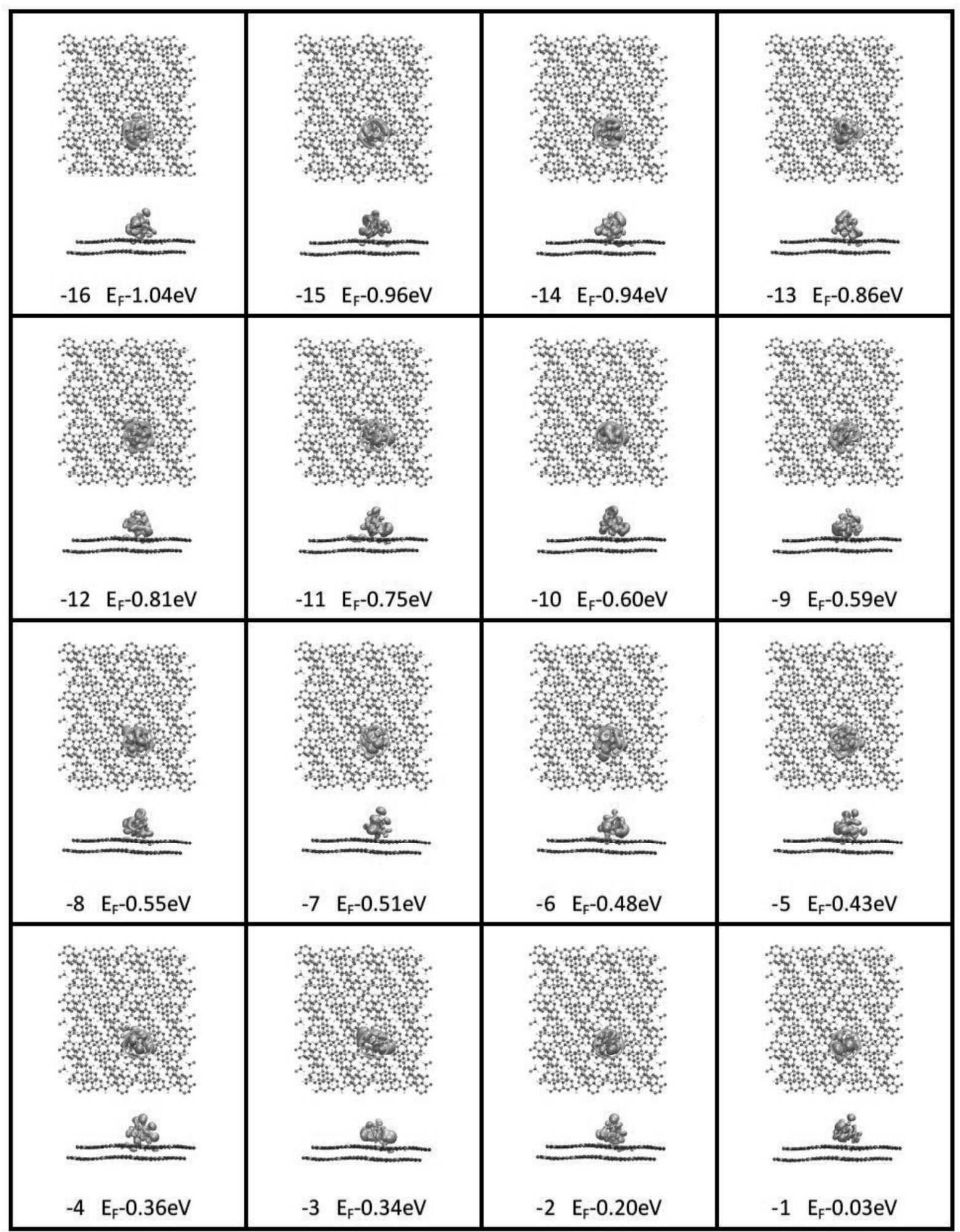

Figure S9 Part 2 of the orbital plots of $\mathrm{Pt}_{13}-\mathrm{Melon}$ from just below the valence band maximum (VBM) to just above the conduction band minimum (CBM) 


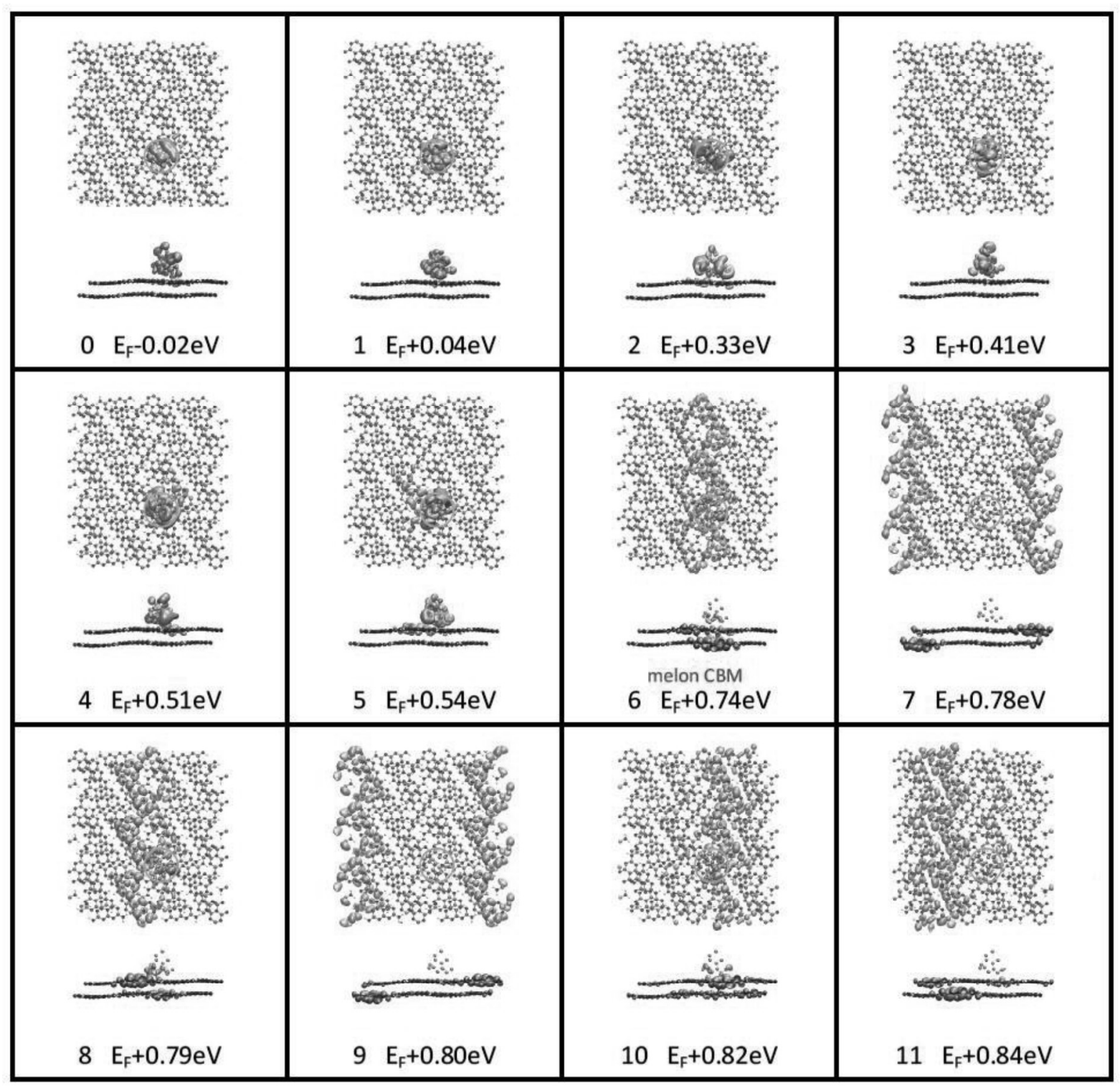

Figure S10 Part 3 of the orbital plots of $\mathrm{Pt}_{13}$-Melon from just below the valence band maximum (VBM) to just above the conduction band minimum (CBM) 


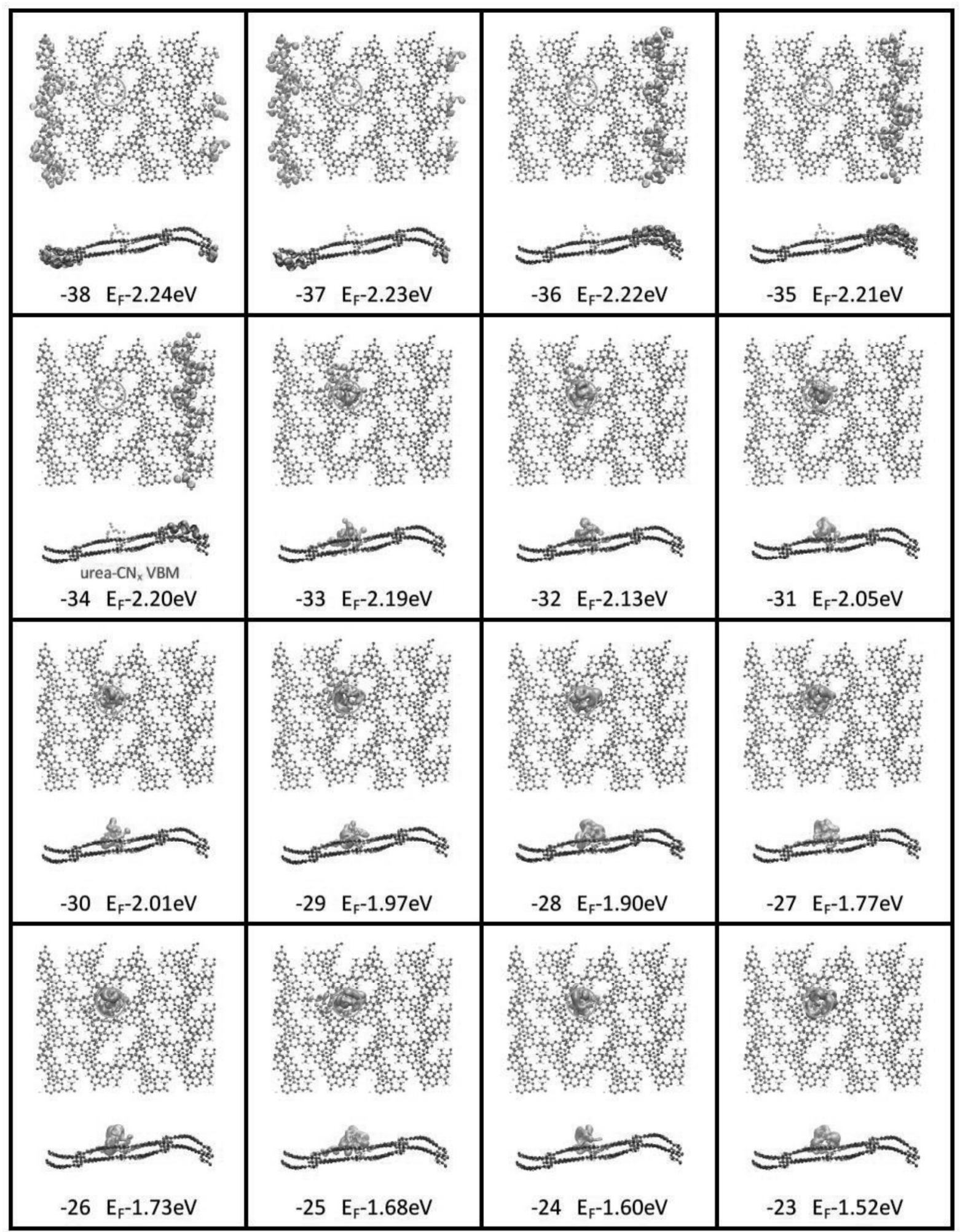

Figure $\mathrm{S} 11$ Part 1 of the orbital plots of $\mathrm{Pt}_{13}$-urea- $\mathrm{CN}_{\mathrm{x}}$ from just below the valence band maximum (VBM) to just above the conduction band minimum (CBM) 


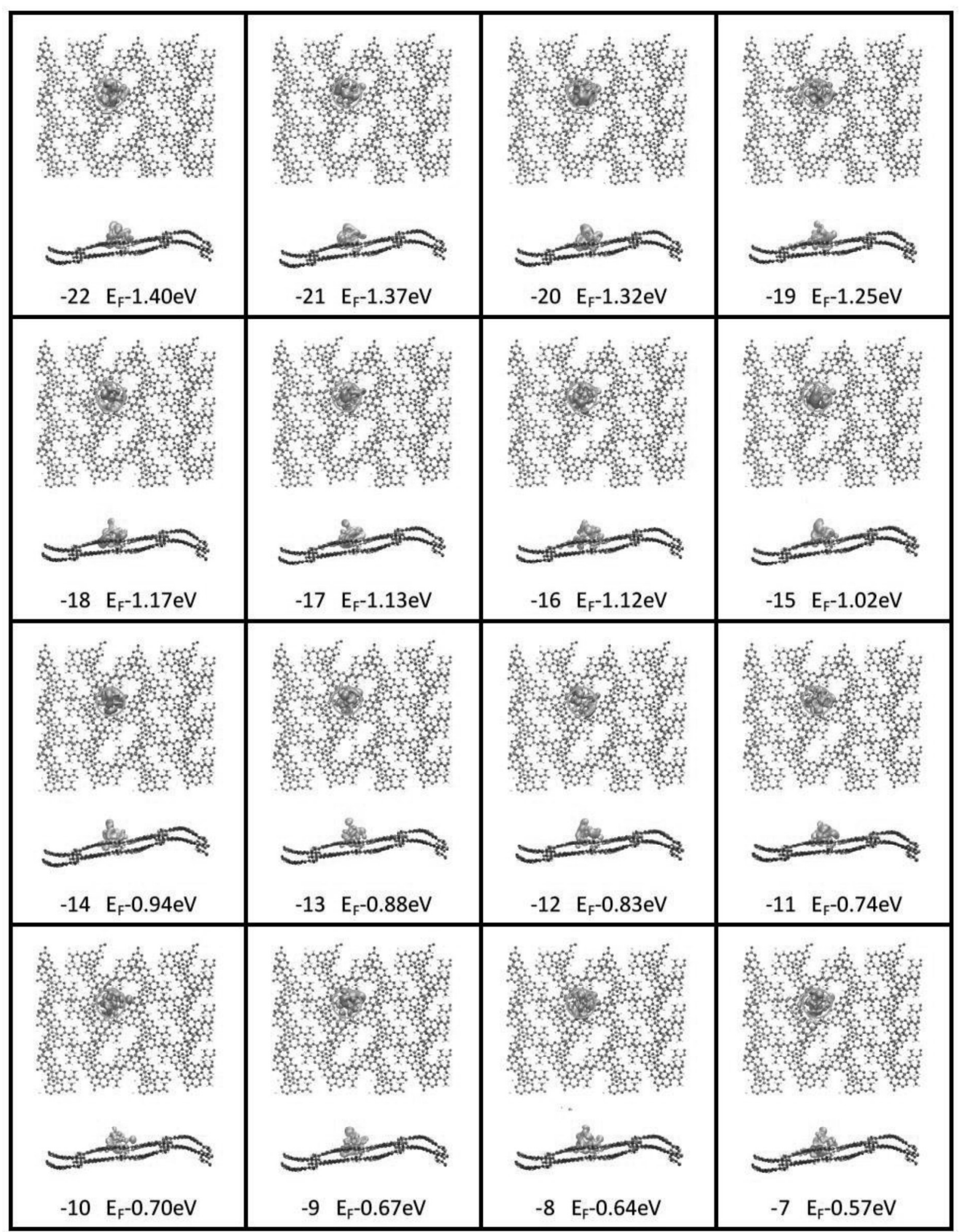

Figure $\mathrm{S} 12$ Part 2 of the orbital plots of $\mathrm{Pt}_{13}$-urea- $\mathrm{CN}_{\mathrm{x}}$ from just below the valence band maximum (VBM) to just above the conduction band minimum (CBM) 


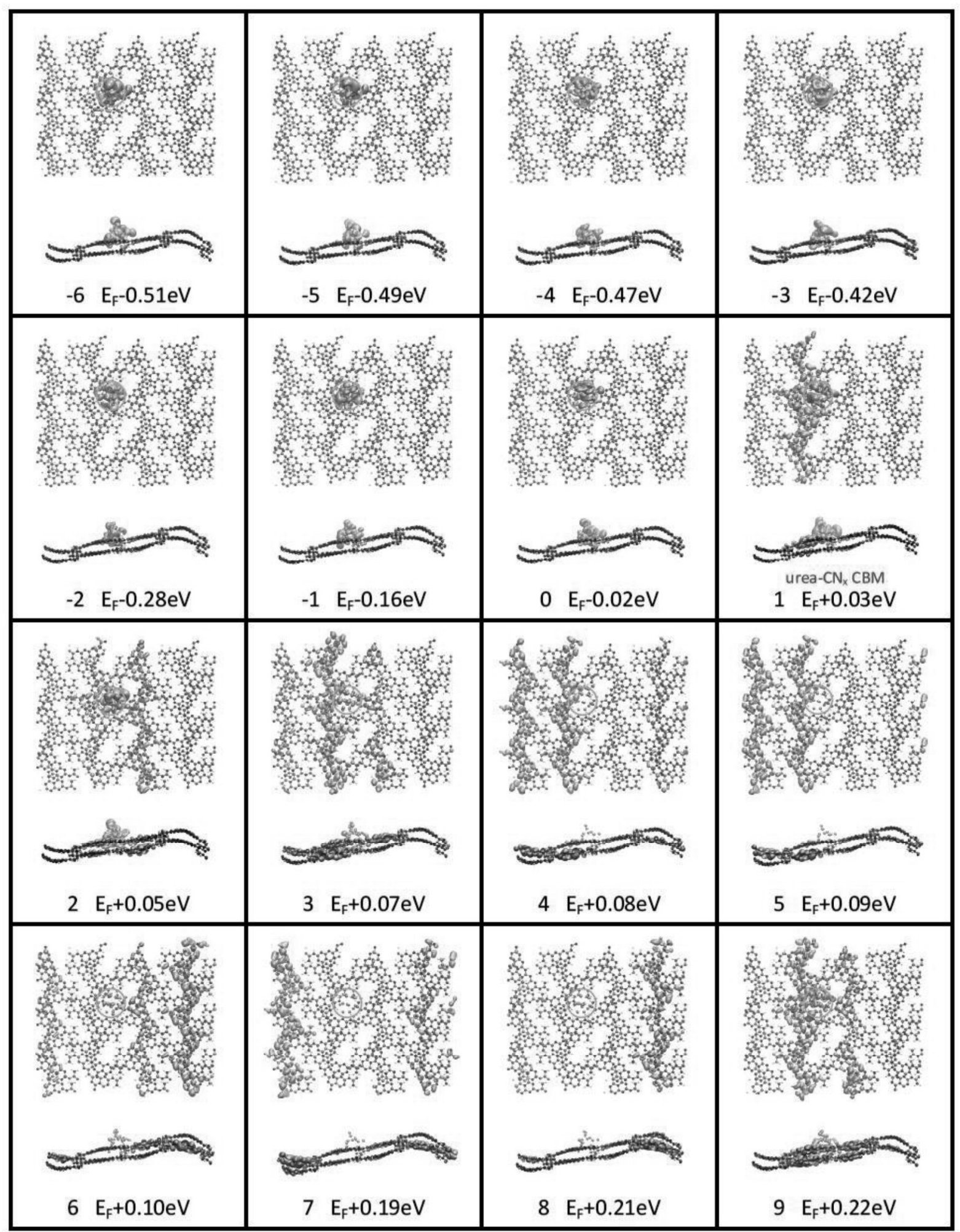

Figure $\mathrm{S} 13$ Part 1 of the orbital plots of $\mathrm{Pt}_{13}$-urea- $\mathrm{CN}_{\mathrm{x}}$ from just below the valence band maximum (VBM) to just above the conduction band minimum (CBM) 
Table S2 Elemental analyses in weight percentages of all spent carbon nitrides studied in this work at the platinum loading optimized for hydrogen evolution.

\begin{tabular}{|c|c|c|c|c|}
\hline & $\mathrm{C}$ & $\mathrm{N}$ & $\mathrm{Pt}$ & Residual Weight (\%) \\
\hline Urea-CN $\mathrm{N}_{\mathrm{x}}$ & $27.9 \pm 0.3$ & $45.0 \pm 0.1$ & $0.77 \pm 0.01$ & 21.2 \\
\hline $\mathrm{NCN}-\mathrm{CN}_{\mathrm{x}} *$ & $27.6 \pm 0.1$ & $43.6 \pm 0.1$ & 5.33 & 23.5 \\
\hline Melon & $33.7 \pm 0.04$ & $57.2 \pm 0.2$ & $0.91 \pm 0.04$ & 8.19 \\
\hline Melon (urea) & $31.3 \pm 0.05$ & $52.5 \pm 0.3$ & $0.83 \pm 0.01$ & 15.4 \\
\hline
\end{tabular}

*Results from reference ${ }^{[8]}$

Table S3 Summary of photocatalytic performance metrics and the BET surface areas

\begin{tabular}{lccccc} 
& Optical gap $(\mathrm{eV})^{*}$ & $\begin{array}{c}\mathrm{H}_{2} \text { evolution rate**} \\
(\mu \mathrm{mol} \mathrm{h})^{-1}\end{array}$ & $\begin{array}{c}\text { Apparent quantum } \\
\text { efficiency }(\%) \dagger\end{array}$ & $\begin{array}{c}\text { BET surface area } \\
\left(\mathrm{m}^{2} \mathrm{~g}^{-1}\right)\end{array}$ & $\begin{array}{c}\text { Intrinsic } \mathrm{H}_{2} \text { evolution ratet } \\
\left(\mu \mathrm{mol} \mathrm{h}^{-1} \mathrm{~m}^{-2}\right)\end{array}$ \\
\hline \hline Urea-CN $\mathrm{CN}_{\mathrm{x}}$ & 2.86 & 56.2 & 17.9 & 64.6 & 43.5 \\
NCN-CN & 2.69 & 24.7 & 9.3 & 54.9 & 22.5 \\
Melon & 2.69 & 2.0 & 0.5 & 16.4 & 6.1 \\
Melon (urea) & 2.74 & 4.4 & 4.7 & 42.3 & 5.2 \\
\hline
\end{tabular}

*Determined from Figure S3

**AM1.5 irradiation, $20 \mathrm{mg}$ photocatalyst, optimized platinum loading and $\mathrm{MeOH}(20 \mathrm{~mL}$ of $10 \mathrm{vol} \%)$ as electron donor

$\uparrow$ As in * but using $400 \pm 20 \mathrm{~nm}$ band pass filter

$\$$ Normalizing the final steady rate of hydrogen evolution under AM1.5 (column 3) with BET surface area (column 5) taking into account that $20 \mathrm{mg}$ of photocatalyst was used in each experiment 


\section{WILEY-VCH}

Table S4 Comparison of the photocatalytic activity for hydrogen evolution, based on AQE values, of the carbon nitrides synthesized in this work and selected visible light active photocatalysts from our group and from the literature.

\begin{tabular}{|c|c|c|c|c|}
\hline Photocatalyst & $\begin{array}{c}\text { Catalyst loading } \\
\text { (mg mL-1) }\end{array}$ & $\begin{array}{l}\mathrm{AQE} \\
(\%)\end{array}$ & $\lambda(\mathbf{n m})$ & $\begin{array}{l}\text { Reactant } \\
\text { solution }\end{array}$ \\
\hline $\mathrm{Pt} /$ Urea-CN $\mathrm{C}$ & 1 & 18 & 400 & $\mathrm{MeOH}$ \\
\hline $\mathrm{Pt} / \mathrm{NCN}-\mathrm{CN}_{\mathrm{x}}$ & 1 & 9 & 400 & $\mathrm{MeOH}$ \\
\hline Pt/Melon (this work) & 1 & 0.5 & 400 & $\mathrm{MeOH}$ \\
\hline Pt/Melem oligomer ${ }^{[6]}$ & 1 & 1 & 400 & $\mathrm{MeOH}$ \\
\hline Pt/Poly(triazine imide $)^{[10]}$ & 1 & Inactive & - & $\mathrm{MeOH}$ \\
\hline Pt/Poly(triazine imide $)^{[10]}$ & 1 & 0.6 & 400 & Triethanolamine \\
\hline $\begin{array}{l}\text { Pt/Poly(triazine imide), 4-amino- } \\
\text { 2,6-dihydroxypyrimidine doped }{ }^{[10]}\end{array}$ & 1 & 0.3 & 400 & $\mathrm{MeOH}$ \\
\hline $\begin{array}{l}\text { Pt/Poly(triazine imide), 4-amino- } \\
2,6 \text {-dihydroxypyrimidine doped } \\
\end{array}$ & 1 & 3 & 400 & Triethanolamine \\
\hline $\mathrm{Pt} /$ Azine $\mathrm{COF}^{[11]}$ & 0.5 & Inactive & - & $\mathrm{MeOH}$ \\
\hline $\mathrm{Pt} /$ Azine $\mathrm{COF}^{[11]}$ & 0.5 & 0.5 & 450 & Triethanolamine \\
\hline Pt/Melon (urea) ${ }^{[7]}$ & 0.43 & 27 & 400 & Triethanolamine \\
\hline Pt/Melon hollow nanosphere ${ }^{[12]}$ & 0.2 & 7.5 & 420 & Triethanolamine \\
\hline $\begin{array}{l}\text { Pt/Poly(triazine imide), } 2,4,6- \\
\text { triaminopyrimidine doped }{ }^{133]}\end{array}$ & 1 & 15 & 400 & Triethanolamine \\
\hline $\mathrm{Pt} / \mathrm{CdS}^{[14]}$ & 26 & 35 & 436 & $\mathrm{Na}_{2} \mathrm{SO}_{3}$ \\
\hline $\mathrm{Pt} / \mathrm{AgInZn}{ }_{7} \mathrm{~S}_{9}{ }^{[14]}$ & 1 & 20 & 420 & $\mathrm{Na}_{2} \mathrm{~S}+\mathrm{K}_{2} \mathrm{SO}_{3}$ \\
\hline $\begin{array}{l}\mathrm{Rh}_{2-\mathrm{x}} \mathrm{Cr}_{\mathrm{x}} \mathrm{O}_{3} / \\
\left(\mathrm{Ga}_{0.88} \mathrm{Zn}_{0.12}\right)\left(\mathrm{N}_{0.88} \mathrm{O}_{0.12}\right)^{[14]}\end{array}$ & 0.81 & 6 & $420-440$ & $\mathrm{H}_{2} \mathrm{SO}_{4}(\mathrm{pH} 4.5)$ \\
\hline
\end{tabular}




\section{WILEY-VCH}

\section{References}

[1] B. M. Fung, A. K. Khitrin, K. Ermolaev, J. Magn. Reson. 2000, 142, 97-101.

[2] a) B.-J. v. Rossum, H. Förster, H. J. M. d. Groot, J. Magn. Reson. 1997, 124, 516-519;

b) A. Lesage, L. Emsley, J. Magn. Reson. 2001, 148, 449-454.

[3] D. Massiot, F. Fayon, M. Capron, I. King, S. L. Calvé, B. Alonso, J.-O. Durand, B. Bujoli, Z. Gan, G. Hoatson, Magn. Reson. Chem. 2002, 40, 70-76.

[4] a) R. Sangill, N. Rastrupandersen, H. Bildsoe, H. J. Jakobsen, N. C. Nielsen, J. Magn. Reson., Ser A 1994, 107, 67-78; b) C. Gervais, F. Babonneau, J. Maquet, C. Bonhomme, D. Massiot, E. Framery, M. Vaultier, Magn. Reson. Chem. 1998, 36, 407-414; c) C. Gervais, J. Maquet, F. Babonneau, C. Duriez, E. Framery, M. Vaultier, P. Florian, D. Massiot, Chem. Mater. 2001, 13, 1700-1707.

[5] a) J. Schaefer, T. A. Skokut, E. O. Stejskal, R. A. McKay, J. E. Varner, Proc. Natl. Acad. Sci. U.S.A. 1981, 78, 5978-5982; b) J. Schaefer, E. O. Stejskal, J. R. Garbow, R. A. McKay, J. Magn. Reson. 1984, 59, 150-156; c) M. Baldus, A. T. Petkova, J. Herzfeld, R. G. Griffin, Mol. Phys. 1998, 95, 1197-1207.

[6] V. W.-h. Lau, M. B. Mesch, V. Duppel, V. Blum, J. Senker, B. V. Lotsch, J. Am. Chem. Soc. 2015, 137, 1064-1072.

[7] D. J. Martin, K. Qiu, S. A. Shevlin, A. D. Handoko, X. Chen, Z. Guo, J. Tang, Angew. Chem. 2014, 53, 9240-9245.

[8] V. W.-h. Lau, I. Moudrakovski, T. Botari, S. Weinberger, M. B. Mesch, V. Duppel, J. Senker, V. Blum, B. V. Lotsch, Nat. Commun. 2016, 7, 12165.

[9] J. Melke, B. Peter, A. Habereder, J. Ziegler, C. Fasel, A. Nefedov, H. Sezen, C. Wöll, H. Ehrenberg, C. Roth, ACS Appl. Mater. Interfaces 2016, 8, 82-90. 


\section{WILEY-VCH}

[10] K. Schwinghammer, B. Tuffy, M. B. Mesch, E. Wirnhier, C. Martineau, F. Taulelle, W. Schnick, J. Senker, B. V. Lotsch, Angew. Chem. Int. Ed. 2013, 52, 2435-2439.

[11] V. S. Vyas, F. Haase, L. Stegbauer, G. Savasci, F. Podjaski, C. Ochsenfeld, B. V. Lotsch, Nat. Commun. 2015, 6, 8508.

[12] J. Sun, J. Zhang, M. Zhang, M. Antonietti, X. Fu, X. Wang, Nat. Commun. 2012, 3, 1139.

[13] M. K. Bhunia, K. Yamauchi, K. Takanabe, Angew. Chem. Int. Ed. 2014, 53, 1100111005.

[14] A. Kudo, Y. Miseki, Chem. Soc. Rev. 2009, 38, 253-278. 
Click here to access/download Supporting Information urea_cnx_bilayer.cif 
Click here to access/download Supporting Information urea_cnx_bilayer_pt.cif 
Click here to access/download

Supporting Information melon_bilayer.cif 
Click here to access/download Supporting Information melon_bilayer_pt.cif 
Click here to access/download

Production Data

Figure 1.pdf 
Click here to access/download

Production Data

Figure 2.pdf 
Click here to access/download

Production Data

Figure 3.pdf 
Click here to access/download

Production Data

Figure 4.pdf 
Click here to access/download

Production Data

Figure 5.pdf 
Click here to access/download

Production Data

Figure 6.pdf 
Click here to access/download

Production Data

figure7_v3.tif 
Click here to access/download

Production Data

Figure 8.pdf 
Click here to access/download Production Data Scheme 1.pdf 
Click here to access/download

Production Data

Scheme 2.pdf 
Click here to access/download

Production Data

Graphical-abstract.jpg 